Faculty of Science

Faculty Publications

Turbulent Collapse and Recovery in the Stable Boundary Layer Using an Idealized Model of Pressure-Driven Flow with a Surface Energy Budget

Amber M. Holdsworth and Adam H. Monahan

May 2019

(c) 2018 American Meteorological Society (AMS).

This article was originally published at:

https://doi.org/10.1175/JAS-D-18-0312.1

Citation for this paper:

Holdsworth, A.M. \& Monahan, A.H. (2019). Turbulent Collapse and Recovery in the Stable Boundary Layer Using an Idealized Model of Pressure-Driven Flow with a Surface Energy Budget. Journal of Atmospheric Sciences, 76(5), 1307-1327. https://doi.org/10.1175/JAS-D-18-0312.1 


\title{
Turbulent Collapse and Recovery in the Stable Boundary Layer Using an Idealized Model of Pressure-Driven Flow with a Surface Energy Budget
}

\author{
Amber M. Holdsworth AND Adam H. Monahan \\ School of Earth and Ocean Sciences, University of Victoria, Victoria, British Columbia, Canada
}

(Manuscript received 18 October 2018, in final form 9 February 2019)

\begin{abstract}
The evolution of the stable boundary layer is simulated using an idealized single-column model of pressure-driven flow coupled to a surface energy budget. Several commonly used parameterizations of turbulence are examined. The agreement between the simulated wind and temperature profiles and tower observations from the Cabauw tower is generally good given the simplicity of the model. The collapse and recovery of turbulence is explored in the presence of a large-scale pressure gradient, but excluding transient submesoscale atmospheric forcings such as internal waves and density-driven currents. The sensitivity tests presented here clarify the role of both rotation and the surface energy budget in the collapse and recovery of turbulence for the pressure-driven dry stable boundary layer (SBL). Conditions of stability are affected strongly by the geostrophic winds, the cloud cover, and the thermal conductivity of the surface. Inertial oscillations and the subsurface temperature have a weaker influence. Particularly noteworthy is the relationship between SBL regime and the relative importance of the terms in the surface energy budget.
\end{abstract}

\section{Introduction}

The atmospheric boundary layer (ABL) is the layer of the troposphere that is directly influenced by Earth's surface. The depth of this layer varies in time, ranging in depth from tens of meters to kilometers. In clear-sky conditions the sun warms Earth's surface during the day and generates an unstable surface layer. The resulting convective boundary layer is relatively deep and actively turbulent. Around sunset, when the surface shortwave flux approaches zero, Earth's radiative energy budget changes sign. The resulting cooling gives rise to a nearsurface temperature gradient that marks the onset of the stable boundary layer (van Hooijdonk et al. 2017). Conditions of static stability frequently occur in the Arctic especially during the polar night, and can also occur when warm air is advected over a cold surface.

The stable boundary layer has been classified into different regimes based on the interplay between the temperature gradient and the turbulent transports (Mahrt 2014). The weakly stable boundary layer (wSBL) generally occurs under cloudy skies or in the presence of moderate to strong horizontal pressure gradients

Corresponding author: Amber M. Holdsworth, amber.holdsworth@ dfo-mpo.gc.ca and is characterized by the presence of continuous turbulent mixing. In contrast, the very stable boundary layer (vSBL) typically occurs under clear skies and in the presence of weak horizontal pressure gradients. Under these circumstances turbulence can weaken to the point of cessation. The lower and upper parts of the near-surface flow can largely decouple as strong atmospheric stability inhibits vertical turbulent transport (Derbyshire 1999; Banta et al. 2007; Williams et al. 2013; Mahrt 2011). This phenomenon, referred to as the collapse of turbulence, is a traditional characterization of the transition from the wSBL to the vSBL.

There are many feedbacks that complicate the dynamics of regime transitions in the stable boundary layer (SBL). For sufficiently strong temperature gradients turbulent transports of heat from above are weak. Surface cooling further weakens turbulent transports and enhances the inversion. Lower near-surface atmospheric temperatures are associated with a weakening of the downwelling longwave radiation which cools the surface further. These positive feedbacks are counteracted by negative feedbacks such as the fact that decreased surface temperatures result in a lower emission of blackbody radiation which leads to less cooling. Furthermore, cooling of the surface increases the subsurface temperature gradient which can lead to 
warming of the surface as the heat flux to the subsurface increases.

Understanding and predicting the structure of the SBL is important to society (Steeneveld 2014). Human health hazards arise in stable atmospheric conditions when pollutants become trapped near the ground and affect air quality (Nappo 1991; Arya 1999; Salmond and McKendry 2005). Fog and frost formation (Holtslag et al. 2013) has significant consequences for agriculture as well as for ground transportation and aviation. Predictions of the near-surface wind speed are also needed for wind power assessments (Petersen et al. 1998). Any forecast of the future state of the atmospheric boundary layer necessitates the use of models.

Developing an accurate representation of the SBL in weather and climate models is particularly challenging for several reasons. Turbulence occurs on small spatial scales and these subgrid-scale effects must be parameterized. In addition, turbulence can be weak or intermittent and boundary layer depths are so shallow that they are not well resolved. Numerical models on scales from the mesoscale to larger-scale models used for numerical weather prediction (NWP) and climate modeling have particular difficulty representing the dynamics of the very stable boundary layer (Holtslag et al. 2013; Derbyshire 1999; Viterbo et al. 1999). Many atmospheric models use classic Monin-Obukhov similarity theory (MOST) to model the surface layer (Mahrt 1998; Pahlow et al. 2001; Mahrt 2014). This theory assumes that turbulent fluxes scale with their distance from the surface. However, under very stable conditions the scale of turbulent eddies is determined by the stratification independent of the distance from the surface. Therefore, MOST generally holds well in the wSBL, but not in the surface layer of the vSBL (Mahrt 1998; Pahlow et al. 2001).

Under conditions of very strong static stability turbulent transports are weak, which limits the downward sensible heat flux, leading to even colder temperatures at the surface and a further increase of stability. When this positive feedback occurs in models it can lead to runaway cooling giving rise to a cold bias in near-surface temperatures especially during the winter and in polar regions (Derbyshire 1999; Viterbo et al. 1999). To improve the overall model performance, the parameterizations of turbulence used in NWP and climate models are often tuned by altering some of the turbulent process parameters away from observationally based values. One way of tuning the model to avoid conditions of extreme stability is by increasing the magnitude of the turbulent diffusivities (Sandu et al. 2013; Walters et al. 2014). A common justification of these enhanced mixing schemes is the argument that they represent localized mixing events that are not explicitly accounted for due to submesoscale motions such as density-driven currents, solitary waves, and internal gravity waves (Sandu et al. 2013). However, artificially enhanced diffusion can lead to a warm bias near the surface in cold conditions and cloud dissipation (Tjernström et al. 2005; Sandu et al. 2013; Holtslag et al. 2013). The improvement of parameterizations that account for physical processes such as gravity waves, flow over topography, and other mesoscale motions requires improved understanding of the physical mechanisms governing turbulent transitions.

As the wSBL-vSBL transition is primarily radiatively driven (over land), idealized models of this process have not needed to account for Coriolis effects or mechanical driving by the large-scale pressure gradient force (ReVelle 1993; Van de Wiel et al. 2007; Acevedo et al. 2012; Van de Wiel et al. 2012a,b; Holdsworth et al. 2016). Van de Wiel et al. (2007) showed that a simple Couette flow model with fixed surface sensible heat flux was able to qualitatively represent transitions from the wSBL to the vSBL. The transition was explained by appealing to the idea of a maximum sustainable heat flux (MSHF) (Van de Wiel et al. 2012b): the sensible heat flux is limited to a maximum under the influence of strong temperature gradients because turbulent transports are suppressed by the stratification, and in nearneutral conditions by the weak temperature gradient. The maximum heat flux occurs under conditions of intermediate stability. If the surface radiative energy flux exceeds this maximum, the downward transport of energy cannot meet this demand and rapid surface cooling occurs. Holdsworth et al. (2016) showed that the transition behavior of Couette flow described by the MSHF framework is qualitatively insensitive to the parameterization of turbulence, and that when the flow is dynamically unstable only one unstable mode exists. They confirmed the conjecture that for this system weakly stable and very stable regimes corresponded to the dynamically stable and dynamically unstable branches, respectively (Taylor 1971; Van de Wiel et al. 2007, 2012a; Holdsworth et al. 2016). Monahan et al. (2015) classified the observations from the Cabauw Experimental Site for Atmospheric Research (CESAR) in the Netherlands $\left(51.971^{\circ} \mathrm{N}, 4.927^{\circ} \mathrm{E}\right)$ (Van Ulden and Wieringa 1996) into two distinct regimes using hidden Markov model analysis, which corresponded well to the unstable and stable branches. However, these Couette flow models assume that the heat flux at the surface is fixed, while in the atmosphere the heat flux varies as a function of the surface energy budget.

Van de Wiel et al. (2017) used a conceptual model that combined the effects of soil heat transport and radiative 
budget together and considered the "coupling strength" between the surface and the lower atmosphere. They compared this model to observations from Cabauw and Dome $\mathrm{C}$ in Antarctica and showed that the differences between these cases can be interpreted in terms of changes in the coupling strength. Many models of the SBL have assumed a prescribed surface sensible heat flux (Gohari and Sarkar 2017) and a relatively shallow fixed height for the boundary layer (Van de Wiel et al. 2007, 2012a; Acevedo et al. 2012; McNider et al. 1995). Since the heat flux varies depending on the properties of the underlying surface, coupling the simulated atmosphere with the surface energy budget allows for an interdependence between the surface temperature and the surface sensible heat flux (Steeneveld et al. 2006).

The idea that there exists a critical wind speed that marks the transition between the wSBL and the vSBL can be traced at least as far back at Nieuwstadt (1984), who restricted his analysis of the SBL to wind speeds above $5 \mathrm{~m} \mathrm{~s}^{-1}$ to ensure continuous turbulence. Transition wind speeds from 3 to $7 \mathrm{~m} \mathrm{~s}^{-1}$ have been reported (Van de Wiel et al. 2012a; Acevedo et al. 2012; Van de Wiel et al. 2012b). Denoting the transition wind speed by $U_{\text {min }}$, Van Hooijdonk et al. (2015) defined the shear capacity as the dimensionless ratio $U / U_{\min }$ so that the wSBL is separated from the vSBL at $U / U_{\min }=1$. While this parameter provides a useful heuristic, the estimated value of $U_{\min }$ is empirically based using clearsky data at Cabauw and may not be generalizable. Similarly, Sun et al. (2012) found that for a given height the relationship between turbulence intensity and mean wind speed changes for a critical (transition) value of the wind speed. This criterion is referred to as the hockey-stick transition (HOST) since the relationship resembles a hockey stick where the elbow of the stick marks the transition wind speed (Sun et al. 2015, 2016). Still, the connection between the coupling strength of the surface and this transition wind speed is not well understood.

In this study we develop an idealized single-column model to examine the collapse and recovery of turbulence in the SBL under the influence of a large-scale pressure gradient force, the effect of rotation, and an explicit model of the surface that separates the factors controlling the coupling strength. The model is described in section 2 . In section 3 a the sensitivity of the model to different parameterizations of turbulence is explored. Section $3 \mathrm{~b}$ examines the role of rotation in the development and evolution of the SBL as a function of the pressure gradient force (geostrophic wind). In section $3 \mathrm{c}$ we explore the role of different variables influencing the surface energy budget such as the cloud cover, surface type, and the subsurface temperature on regime transitions. Discussion of the results is presented in section 4 and the conclusions appear in section 5 .

\section{Numerical model}

A schematic diagram of our idealized single-column model (SCM) of pressure-driven flow in the dry SBL assuming horizontal homogeneity is shown in Fig. 1. This model was developed by the present authors and was used in the related study of van Hooijdonk et al. (2017). The model equations follow those of Blackadar (1979):

$$
\begin{aligned}
& \frac{\partial U}{\partial t}=\frac{1}{\rho} \frac{\partial \tau_{x}}{\partial z}-\frac{1}{\rho} \frac{\partial p}{\partial x}+f_{0} V, \\
& \frac{\partial V}{\partial t}=\frac{1}{\rho} \frac{\partial \tau_{y}}{\partial z}-\frac{1}{\rho} \frac{\partial p}{\partial y}-f_{0} U, \\
& \frac{\partial T}{\partial t}=-\frac{1}{\rho c_{p}} \frac{\partial H}{\partial z}-C_{\mathrm{HL}}, \\
& \frac{\partial T_{s}}{\partial t}=C_{1}\left(I_{\mathrm{lw}}-\sigma T_{s}^{4}-H_{0}\right)-C_{2}\left(T_{s}-T_{d}\right),
\end{aligned}
$$

where the three state variables $U(z, t), V(z, t)$, and $T(z, t)$ are the zonal velocity, meridional velocity, and potential temperature. For later reference we define the speed $S=\left(U^{2}+V^{2}\right)^{0.5}$. The constant $C_{\mathrm{HL}}=2 \mathrm{~K} \mathrm{~h}^{-1}$ represents the atmospheric cooling due to net longwave radiative flux divergence, set as a fixed constant for simplicity. This particular value was chosen based on observational estimates and is discussed further in section 2 . The model contains several constants that are listed in Table 1 for reference.

The geostrophic wind components are defined by $U_{g}=-\left(1 / f_{0} \rho\right)(\partial p / \partial y)$ and $V_{g}=\left(1 / f_{0} \rho\right)(\partial p / \partial x)$, and $S_{g}=\left(U_{g}^{2}+V_{g}^{2}\right)^{0.5}$ is the geostrophic wind speed. For simulations without rotation $\left(f_{0}=0\right)$, Eq. (2) is eliminated leaving only two state variables $T(z, t)$ and $U(z, t)$. For reference, the relationship between $S_{g}$ and the corresponding pressure gradient is shown for $f_{0}=10^{-4} \mathrm{~s}^{-1}$ with a thin red line in Fig. 2.

The vertical heat flux $H=\rho c_{p} \overline{W^{\prime} T^{\prime}}$ and shear stresses $\tau_{x}=-\rho \overline{U^{\prime} W^{\prime}}$ and $\tau_{y}=-\rho \overline{V^{\prime} W^{\prime}}$ (where $W$ is the vertical velocity) are parameterized using first-order closure $\tau_{x} / \rho=K_{m} \partial_{z} U, \tau_{y} / \rho=K_{m} \partial_{z} V$, and $H / \rho c_{p}=-K_{H} \partial_{z} T$. The diffusivities are taken to be the sum of molecular and turbulent contributions (Moene et al. 2010)

$$
\begin{gathered}
K_{m}=l^{2}\left|\partial_{z} U\right| f_{m}(\mathrm{Ri})+\nu, \\
K_{h}=l^{2}\left|\partial_{z} U\right| f_{h}(\mathrm{Ri})+\lambda,
\end{gathered}
$$




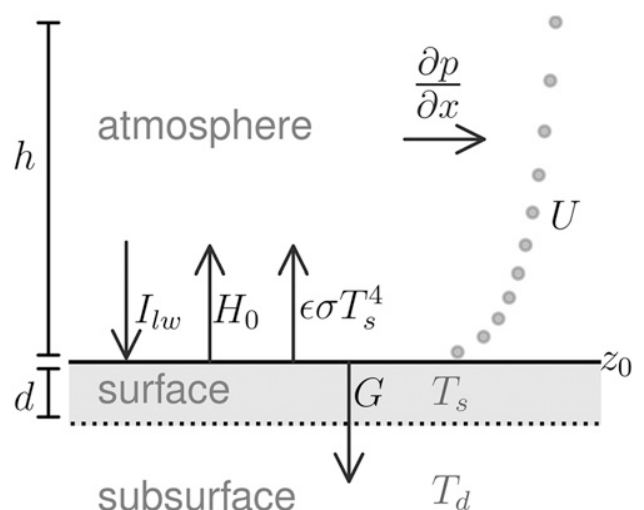

FIG. 1. Schematic diagram for the SCM of pressure-driven flow in the SBL including a force-restore surface radiative budget. Here $T_{s}$ is the surface temperature, $T_{d}$ is the subsurface temperature, $z_{0}$ is the surface roughness, $p$ is the pressure, $d$ is the depth of the subsurface layer, $I_{\mathrm{lw}}$ is longwave downwelling radiation, $H_{0}$ is the surface heat flux, and $G$ is the heat flux into the subsurface.

where the molecular contribution $\nu=1.5 \times 10^{-5} \mathrm{~m}^{2} \mathrm{~s}^{-1}$ is the kinematic viscosity. Molecular shear stresses are constant in the thin viscous sublayer near the surface where molecular viscosity dominates. The friction velocity is uniformly distributed throughout the thin sublayer and defined in terms of the wall shear stress $u_{0 *}^{2}=\tau_{0} / \rho$ where $\tau_{0}=\rho \nu \partial_{z} U$. The molecular Prandtl number is fixed at $\operatorname{Pr}=0.72$ which is typical for the atmosphere (Kundu et al. 1990) and $\lambda=\nu / \operatorname{Pr}$ is the molecular diffusivity. The mixing length is given by

$$
l=\left[1-\exp \left(-\frac{u_{0 *} z}{C \nu}\right)\right]\left[\frac{\kappa\left(z-z_{0}\right)}{1+\kappa\left(z-z_{0}\right) / \lambda_{0}}\right],
$$

with $C=26$ (Van Driest 1951) and $\lambda_{0}=0.00027 S_{g} / f_{0}$ (Blackadar 1962).

The stability functions $f_{m, h}(\mathrm{Ri})$, which will be discussed in more detail in section $3 \mathrm{a}$, depend on the Richardson number $\mathrm{Ri}=\left(g / T_{\mathrm{REF}}\right)\left[\partial_{z} T /\left(\partial_{z} U\right)^{2}\right]$. The stability functions are related to the similarity functions from MOST $\phi_{m, h}(\zeta)$ by

$$
\begin{aligned}
& f_{m}\left(\mathrm{Ri}_{\mathrm{eq}}\right)=\phi_{m}^{-2}(\zeta), \\
& f_{h}\left(\mathrm{Ri}_{\mathrm{eq}}\right)=\phi_{m}^{-1}(\zeta) \phi_{h}^{-1}(\zeta),
\end{aligned}
$$

where $\zeta=z / L$ is the stability parameter and $L=$ $-u_{*}^{2} /\left[\kappa\left(g / T_{s}\right)\left(H_{0} / c_{p} \rho\right)\right]$ is the Obukhov length. Although the present investigation is restricted to the nocturnal boundary layer, conditions of static instability occasionally arise, in which case the Dyer (1974) function is used with $\zeta<0$.

The upper boundary of the model, at which we impose

\begin{tabular}{|c|c|c|}
\hline Parameter & Description & Value/units \\
\hline$T_{s}$ & $\begin{array}{l}\text { Temperature at the } \\
\text { surface (slab layer) }\end{array}$ & K \\
\hline$T_{d}$ & $\begin{array}{l}\text { Mean temp of subsurface } \\
\text { layer }\end{array}$ & $\mathrm{K}$ \\
\hline$H_{0}$ & $\begin{array}{l}\text { Heat flux into the } \\
\text { atmosphere }\end{array}$ & $\mathrm{W} \mathrm{m}^{-2}$ \\
\hline$Q_{a}$ & Specific humidity & $0.003 \mathrm{~kg} \mathrm{~kg}^{-1}$ \\
\hline$Q_{c}$ & Cloud fraction & $0-1$ \\
\hline$\widetilde{\Omega}$ & Earth's angular velocity & $7.27 \times 10^{-5} \mathrm{rad} \mathrm{s}^{-1}$ \\
\hline$C_{s}$ & Volumetric heat capacity & $\rho_{s} c_{s}$ \\
\hline$C_{g}=C_{1}^{-1}$ & $\begin{array}{l}\text { Thermal capacity of a } \\
\text { slab of unit area }\end{array}$ & $0.95\left(\frac{\lambda C_{s}}{2 \omega}\right)^{0.5} \mathrm{~kg} \mathrm{~K}^{-1} \mathrm{~s}^{-2}$ \\
\hline$z_{0}$ & Surface roughness & $0.001 \mathrm{~m}$ \\
\hline$\sigma$ & Stefan-Boltzmann constant & $5.669 \times 10^{-8} \mathrm{~W} \mathrm{~m}^{2} \mathrm{~K}^{-4}$ \\
\hline$c_{p}$ & $\begin{array}{l}\text { Specific heat capacity of } \\
\text { dry air }\end{array}$ & $1005 \mathrm{~J} \mathrm{~kg}^{-1} \mathrm{~K}^{-1}$ \\
\hline$\rho$ & Density of air & $1.2 \mathrm{~kg} \mathrm{~m}^{-3}$ \\
\hline$g$ & Gravity constant & $9.81 \mathrm{~m} \mathrm{~s}^{-2}$ \\
\hline$\kappa$ & Von Kármán constant & 0.4 \\
\hline
\end{tabular}
the boundary condition that the flow is geostrophic, is
TABLE 1. List of model parameters (independent variables).

fixed at $h=5000 \mathrm{~m}$. This domain is large enough for the height of the SBL to evolve freely for the geostrophic wind speeds used in this study (varying between 2 and $30 \mathrm{~m} \mathrm{~s}^{-1}$ ). At the upper boundary a no-flux condition is implemented so that the sensible heat flux $H_{h}=0$ and turbulent momentum flux $\tau_{h}=0$. The lower boundary of the model domain is determined by the roughness length of momentum $z_{0}$ where the no-slip boundary conditions $U\left(z_{0}\right)=0$ and $T\left(z_{0}, t\right)=T_{s}(t)$ are applied in which $T_{s}(t)$ is the surface temperature. For simplicity the momentum and temperature roughness lengths are taken to be the same. The height of the boundary layer $h_{\mathrm{BL}}$ is defined as the height at which $H=0.1 H_{0}$. Other definitions of $h_{\mathrm{BL}}$ exist and give similar results to those which follow (Holtslag et al. 2007).

The model implements the surface energy scheme of Blackadar (1976), known as the force-restore method, defined by Eq. (4) and illustrated in Fig. 1. The surface, represented as an infinitesimally thin layer with temperature $T_{s}(t)$ at $z=z_{0}$, is forced by the net radiation and sensible heat flux and restored to the subsurface temperature through the subsurface energy fluxes. A linear temperature profile between the surface and a fixed subsurface temperature is assumed. The damping depth of the diurnal forcing $d=\left(2 \lambda_{s} / C_{s} \omega\right)^{0.5}$, where $C_{s}=\rho_{s} c_{s}$ is the volumetric heat capacity, is associated with a sinusoidal forcing having a time scale of $t_{d}=24 \mathrm{~h}$. The temperature at this depth is set as the subsurface temperature $T_{d}$. In Eq. (4), $C_{1}=2 /\left(0.95 C_{s} d\right)$ and $C_{2}=1.18\left(2 \pi / t_{d}\right)$. The first two terms in Eq. (4) constitute the net longwave radiation $Q_{n}$, the third term is the sensible heat flux into the atmosphere due to turbulent 
(a)

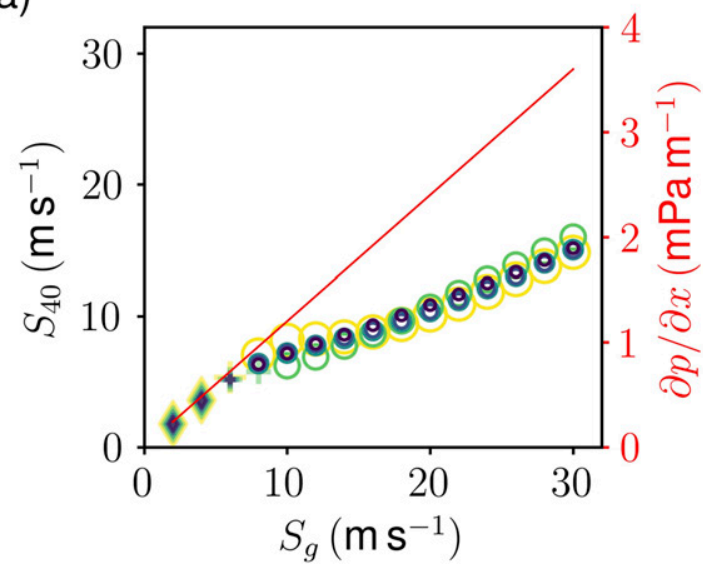

(b)

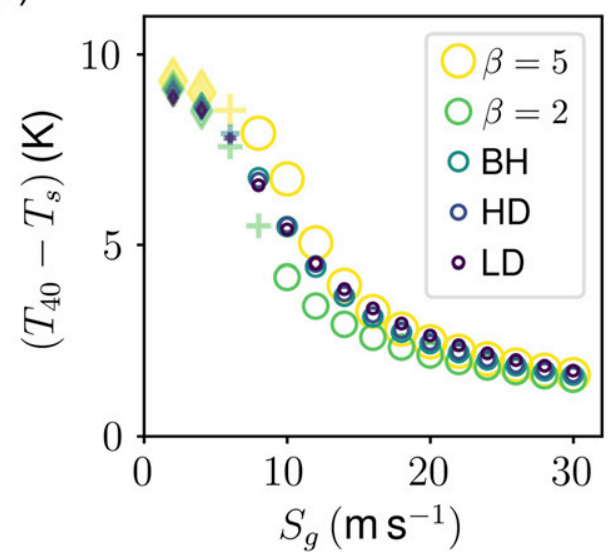

FIG. 2. After $3 \mathrm{~h}$, (a) the wind speed at $40 \mathrm{~m}$ on the primary axis with the horizontal pressure gradient $\partial p / \partial x$ when $f_{0}=10^{-4} \mathrm{~s}^{-1}$ on the secondary axis and (b) the strength of the temperature inversion as a function of the prescribed geostrophic wind $S_{g}$ for each of the stability functions. Here $S_{40}$ and $T_{40}$ are the wind speed and temperature at $40 \mathrm{~m}$, respectively, and $T_{s}$ is the temperature at the surface where $z=z_{0}$.

transports $H_{0}$, and the fourth term is the heat flux into the subsurface $G$. As our focus is on the stably stratified boundary layer we do not include the effects of albedo or latent heat in the heat budget. We also neglect the effects of the vegetation canopy.

We will consider a range of different surface types, with varying mass density $\rho_{s}$, specific heat $c_{s}$, and thermal conductivity $\lambda_{s}$ (Table 2) corresponding to thermal damping depths from about $d=5$ to $20 \mathrm{~cm}$. The longwave downwelling radiation is given by

$$
I_{1 \mathrm{w}}=\sigma\left[Q_{c}+0.67\left(1-Q_{c}\right)\left(1670 Q_{a}\right)^{0.08}\right] T_{a}^{4},
$$

where $Q_{c}$ is the cloud fraction, $Q_{a}$ is the specific humidity, and $T_{a}$ is the atmospheric temperature at a reference level $z_{a}$ just above Earth's surface (Staley and Jurica 1972; Deardorff 1978; McNider et al. 1995; Walters et al. 2007). For simplicity, $Q_{a}$ is held constant at $0.003 \mathrm{~kg} \mathrm{~kg}^{-1}$.

The equations are integrated in time using a fourthorder Runge-Kutta method. The spatial discretization is obtained using finite differences on a logarithmic grid. This grid has 100 vertical levels with a much finer resolution in the boundary layer than aloft and is determined by $z_{j}=\Delta z_{0}\left(r^{j}-1 / r-1\right)$ with a stretch factor $r=\Delta z_{j} / \Delta z_{j-1} \simeq 1.10$ and an initial step size of $\Delta z_{0}=$ $0.05 \mathrm{~m}$. The prognostic variables $U, V$, and $T$ are defined at the $z_{i}$ grid levels, while the diagnostic variables of $H$, $\tau$, and $\mathrm{Ri}$ are defined on $z_{i+1 / 2}$ levels.

We define $t=0$ as the time when the shortwave radiation goes to zero acknowledging the fact that observations from Cabauw indicate that the onset of the SBL can occur before the shortwave radiation goes to zero (van Hooijdonk et al. 2017; van der Linden et al. 2017). The initial conditions were set in accordance with the logarithmic equations that arise from MOST. The near-neutral profiles for temperature and wind used to initialize the model are given by

$$
\begin{aligned}
& U_{0}=\frac{U_{\text {ext }}}{\kappa} \ln \left(z / z_{0}\right), \\
& V_{0}=\frac{V_{\text {ext }}}{\kappa} \ln \left(z / z_{0}\right), \\
& T_{0}=T_{s}+\frac{\theta_{\text {ext }}}{\kappa} \ln \left(z / z_{0}\right),
\end{aligned}
$$

where $U_{\text {ext }}=U_{g} \kappa / \ln \left(h / z_{0}\right), V_{\text {ext }}=V_{g} \kappa / \ln \left(h / z_{0}\right)$, and $\theta_{\text {ext }}=$ $0.01 \mathrm{~K}$ (Monin and Obukhov 1954). For simplicity, we set $\partial p / \partial y=0$ in all of our simulations which means that $U_{0}$ is identically zero at the start of the simulation.

TABLE 2. Molecular thermal properties of different soil types (from Arya 1999).

\begin{tabular}{lccc}
\hline \hline Material & $\begin{array}{c}\text { Mass density } \rho_{s} \\
\left(\mathrm{~kg}^{-1} \mathrm{~K}^{-3} \times 10^{-3}\right)\end{array}$ & $\begin{array}{c}\text { Specific heat } c_{s} \\
\left(\mathrm{~J} \mathrm{~kg}^{-1} \mathrm{~K}^{-1} \times 10^{-3}\right)\end{array}$ & $\begin{array}{c}\text { Thermal } \\
\text { conductivity } \lambda_{s} \\
\left(\mathrm{~W} \mathrm{~m}^{-1} \mathrm{~K}^{-1}\right)\end{array}$ \\
\hline Water & 1.00 & 4.18 & 0.57 \\
Ice & 0.92 & 2.10 & 2.24 \\
Dry sand & 1.60 & 0.80 & 0.30 \\
Dry clay & 1.60 & 0.89 & 0.25 \\
Wet clay & 2.00 & 1.55 & 1.58 \\
Rock & 2.70 & 0.75 & 2.90 \\
Fresh snow & 0.10 & 2.09 & 0.08 \\
Old snow & 0.48 & 2.09 & 0.42 \\
\hline
\end{tabular}




\section{Results}

To explore the collapse and recovery of turbulence in the SBL under different environmental conditions and external forcings it is useful to define a criterion for turbulent collapse. The classical criterion is that turbulence will collapse when the gradient Richardson number exceeds a critical value, many values of which have been suggested in the literature (Webb 1970; Businger et al. 1971; Businger 1973; Taylor 1931; Holtslag et al. 1990; Mahrt 1981). These studies have found that turbulence is not necessarily quiescent after the critical value is exceeded (Grachev et al. 2013). We will use a bulk Richardson number with a critical value of $\mathrm{Ri}_{c}=0.25$. This is within the range $\mathrm{Ri}_{c}=0.20-0.25$ reported for the Surface Heat Budget of the Arctic Ocean (SHEBA) experiment (Grachev et al. 2013). The bulk Richardson number has the advantage that it can be straightforwardly calculated for observations from a wind tower using the formula

$$
\mathrm{Ri}_{B}=\frac{\frac{g}{T_{\mathrm{REF}}} \Delta T}{\Delta U^{2}+\Delta V^{2}} .
$$

The vertical differences will be calculated between $z=$ 40 and $1.5 \mathrm{~m}$ (screen height). Other criteria that make use of a transition wind speed have been explored (Van Hooijdonk et al. 2015; Sun et al. 2012).

The HOST criterion was first applied to the 1999 Cooperative Atmosphere-Surface Exchange Study (CASES-99) (Sun et al. 2012) and has been applied in several subsequent studies (i.e., Mahrt et al. 2015; Russell et al. 2016; Maroneze et al. 2019). The criterion relates the mean horizontal wind speed to the turbulent intensity at a given height. These quantities were averaged in time to capture fluctuations. To apply the HOST criterion to our model results, we use the timeaveraged horizontal wind speed $\bar{S}$ and the friction velocity as a measure of the turbulent intensity. Since, the model output frequency is $5 \mathrm{~min}$, we use a minimal averaging window of $10 \mathrm{~min}$ and a height of $10 \mathrm{~m}$. Figure 3 shows that the relationship between $\bar{S}$ and $u *$ is broadly consistent with Sun et al. (2015) (Figs. 4a,b). However, the contrast between the two regimes is sharper in the observations than it is in our model which is indicative of model biases in representing the vSBL. The transition wind speed that is predicted by the Richardson number criterion is shown with a dashed line and is about $S_{g}=8 \mathrm{~m} \mathrm{~s}^{-1}$. The geostrophic wind at the elbow of the hockey stick is in agreement with the transition wind speed predicted by the critical Richardson number. Because both criteria lead to a similar transition wind speed for our simulations,



FIG. 3. The relationship between the mean horizontal wind speed $\bar{S}$ and the friction velocity $u *$ for the control simulations. Values were taken at a height of $10 \mathrm{~m}$ by averaging over $10 \mathrm{~min}$.

we will use the simply defined Richardson number criterion for convenience.

Figure 3 a demonstrates that when turbulence is said to collapse there is still some turbulent activity. The collapse of turbulence is the transition from the wSBL to the vSBL and the recovery is the transition from the vSBL to the wSBL.

\section{a. Choice of parameterization}

The stability functions used to parameterize the turbulent diffusivities were largely formulated using empirical fits to atmospheric data. These functions are subject to large uncertainty and problems with sampling (Nieuwstadt 1984; Mahrt 1985) especially in the very stable regime (Clarke 1970; Webb 1970; Businger et al. 1971; Hicks 1976; Holtslag and De Bruin 1988; Chenge and Brutsaert 2005; Brown et al. 2008). This fact has been used to justify the modifications of these functions to improve model performance (Sandu et al. 2013). A commonly used expression for the similarity functions is $\phi_{m, h}(\zeta)=1+\beta \zeta$ where $\beta=1 / \mathrm{Ri}_{c}$. While this function first appeared in Monin and Obukhov (1954), it is generally referred to as the Businger-Dyer function (Businger 1988). The value of the universal constant $\beta$ varies in the literature taking the values 2 (Pruitt et al. 1973), 4.7 (Businger et al. 1971), 5.2 (Webb 1970), and even 7 (McVehil 1964). However, it is widely accepted that the linear stability functions proposed by Businger et al. (1971) are not adequate for $z / L>1$ (Carson and Richards 1978; Howell and Sun 1999; Nieuwstadt 1984). In addition to the Businger et al. (1971) (BD) function with $\beta=2$ (BD2) and 5 (BD5), we will consider the Holtslag and De Bruin (1988) (HD) 

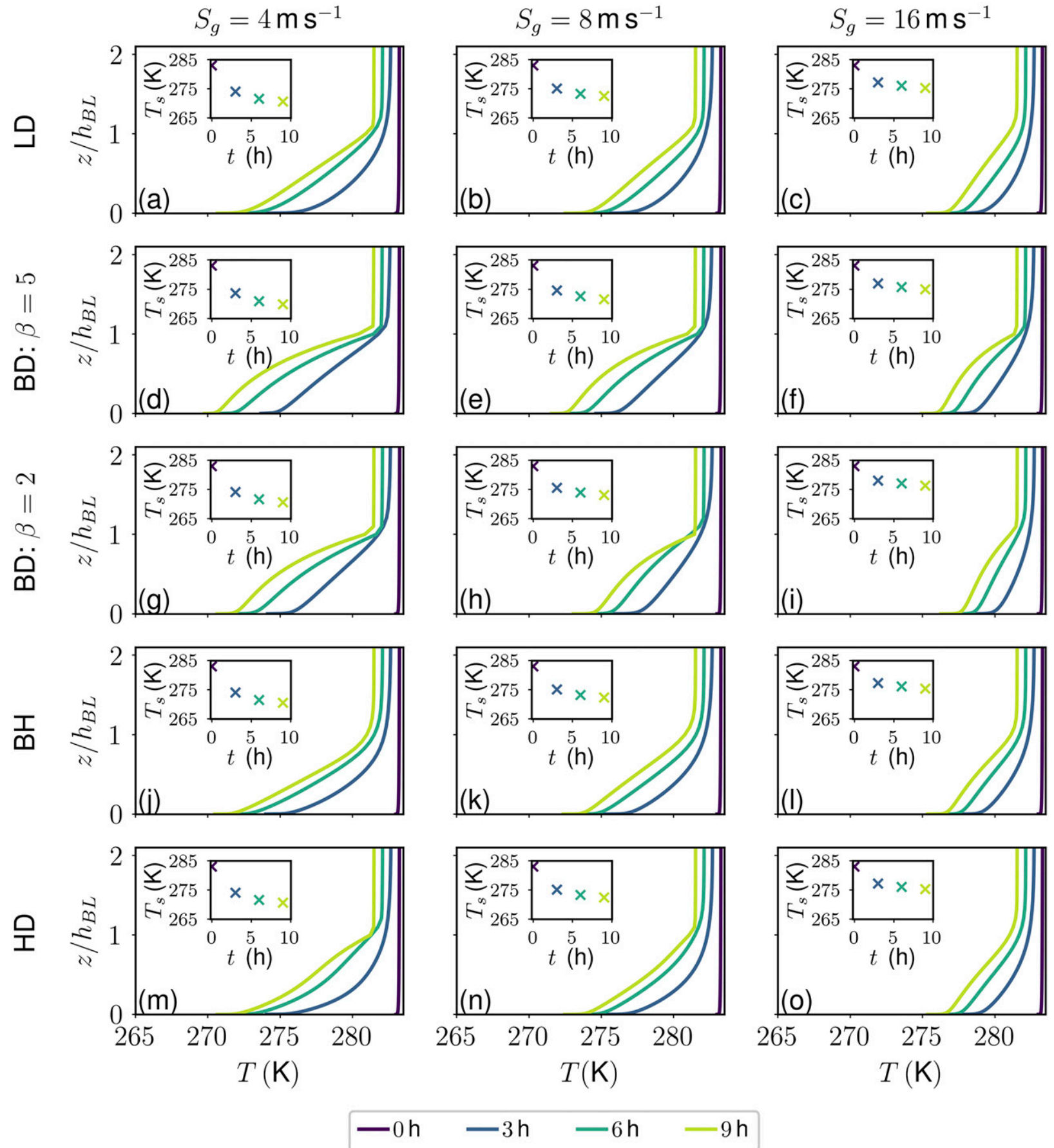

FIG. 4. Temperature profiles for different (top to bottom) stability functions and (left to right) geostrophic wind speeds at the times indicated by the legend at the bottom. The height is nondimensionalized by the height of the boundary layer. The inset plots show the evolution of the surface temperature.

function, the Beljaars and Holtslag (1991) (BH) function which is currently used by the European Centre for Medium-Range Weather Forecasts (ECMWF) operational model (ECMWF 2013) and the Louis-Delage (LD; Louis 1979; Delage 1997) function which is currently in use by the Canadian Meteorological Centre's Global Deterministic Prediction System (GDPS). Some of these formulations imply the existence of a critical Richardson number (Businger et al. 1971; Holtslag and De Bruin 1988) and others do not (Beljaars and Holtslag 1991; 
Delage 1997). The formulas for these functions can be found in Table 1 of Holdsworth et al. (2016) except for Delage (1997). The formula for that function was incorrectly stated in Holdsworth et al. (2016) and is actually a modified version of the Louis (1979) function given by $f_{m, h}(\mathrm{Ri})=(1+12 \mathrm{Ri})^{-2}$.

The surface parameters for the control simulation correspond to dry sand (Table 2) with $z_{0}=0.001 \mathrm{~m}$ (typical for Cabauw; Bosveld et al. 2014), clear skies $\left(Q_{c}=0\right), T_{d}=281 \mathrm{~K}$, and an initial surface temperature of $T_{s}=283 \mathrm{~K}$. These surface characteristics are similar to those used in previous model studies (ReVelle 1993; McNider et al. 1995; Edwards 2009b). The grasscovered soil at Cabauw consists of up to $50 \%$ clay and the thermal conductivity varies with the level of soil moisture (Bosveld 2018). Given the differences in the soil characteristics and the idealized nature of our model, exact quantitative agreement with Cabauw observations is not expected, but the parameters are close enough for a qualitative comparison. The observed temperature profiles from Cabauw indicate a steady temperature tendency due to longwave radiative flux divergence of approximately $C_{\mathrm{HL}}=2 \mathrm{~K} \mathrm{~h}^{-1}$ at each vertical level (cf. Fig. 5 of van der Linden et al. 2017). The same value was used by Acevedo et al. (2012).

The evolution of the temperature profile normalized by the time-evolving height of the boundary layer for the different stability functions is shown in Fig. 4. Each column represents a different geostrophic wind speed (as indicated at the top). These speeds were selected to be representative of speeds in the vSBL, near the transition wind speed, and in the wSBL, respectively. Inset plots of surface temperature show that, consistent with the air temperature profiles, cooling near the surface is generally smaller for larger $S_{g}$. The BD profiles are similar in shape with differences attributed to the fact that smaller $\mathrm{Ri}_{c}$ results in more pronounced surface cooling because mixing goes to zero at a relatively weak static stability. The BH, HD, and LD functions all have similar shapes except in the vSBL where there are pronounced differences in curvature with the HD function.

Figure $2 \mathrm{~b}$ shows the inversion strength as a function of the geostrophic wind at $t=3 \mathrm{~h}$. The strength of the simulated inversion is calculated as the temperature difference between $40 \mathrm{~m}$ and the lowest model level. All of the formulations exhibit similar dependence of inversion strength on $S_{g}$. The inversion strengths are more sensitive to $S_{g}$ for relatively weak pressure gradients and reach values of around $9 \mathrm{~K}$. This finding is consistent with the stratifications observed at Cabauw (Van de Wiel et al. 2017) (cf. Fig. 1) where there was a factor of $\simeq 4$ difference between the inversion strengths of the lowest and highest wind speeds measured in the observations $\left(S_{g}=3-16 \mathrm{~m} \mathrm{~s}^{-1}\right)$. Similar correspondence is found with Baas et al. (2018) (cf. Fig. 4) and van der Linden et al. (2017) (cf. Fig. 9) when the temperature inversions are calculated at heights consistent with their calculations (not shown).

In Fig. $2 b$ the solid diamond markers indicate cases of turbulent collapse, crosses indicate cases with turbulent collapse and recovery, and the open circles indicate a persistent wSBL. For the BD function with $\beta=2$, the vSBL-wSBL transition occurs at a larger $S_{g}$ than for the other functions.

Several previous studies have related the temperature inversion to the geostrophic winds (van der Linden et al. 2017; Baas et al. 2018) or to the speed at a fixed height above the surface $S_{40}$ (Van de Wiel et al. 2017; Vignon et al. 2017). Baas et al. (2018) showed that the transition from the vSBL to wSBL was more gradual with changes of $S_{g}$ than with changes in the wind speed at a fixed height because of the nonlinear relationship between these two speeds. The relationship between $S_{40}$ and $S_{g}$ is shown for each of the similarity functions in Fig. 2a when $t=3 \mathrm{~h}$. For very small $S_{g}$ the boundary layer is shallow so the winds are close to geostrophic at $S_{40}$. As $S_{g}$ increases the boundary layer deepens and the speed at $40 \mathrm{~m}$ is subgeostrophic. Later in the night, $S_{40}$ becomes supergeostrophic for $S_{g}=4-8 \mathrm{~m} \mathrm{~s}^{-1}$ as a consequence of inertial oscillations.

Figure 5 shows the wind speed and temperature profiles at $t=6 \mathrm{~h}$ for all of the stability functions with $S_{g}=4 \mathrm{~m} \mathrm{~s}^{-1}$ in the top row (vSBL) and $16 \mathrm{~m} \mathrm{~s}^{-1}$ in the bottom row (wSBL). In the wSBL, the profiles resulting from the $\mathrm{BD} 2, \mathrm{HD}, \mathrm{LD}$, and $\mathrm{BH}$ functions have shapes that are similar to the Cabauw profiles (cf. Fig. 5 of van der Linden et al. 2017). In particular, the wind speed profiles reach a maximum near the top of the stable layer (at about $200 \mathrm{~m}$ aloft) whereas the BD5 function results in an unrealistically shallow boundary layer. Supergeostrophic wind at the top of the inversion layer is often referred to as a low-level jet. The low-level jet is more pronounced and occurs nearer to the surface for functions with relatively small $\mathrm{Ri}_{c}$. There are substantial quantitative differences in the profile shapes for the different functions with the $\mathrm{HD}, \mathrm{BH}$, and $\mathrm{LD}$ functions exhibiting the closest agreement with the shape of the observed Cabauw profiles (cf. Fig. 5 of van der Linden et al. 2017) for both regimes, although the model underestimates the depth of the boundary layer in the vSBL for all stability functions. This bias could be due in part to the initial conditions chosen, but it also highlights the inability of these parameterizations to capture the weak or intermittent behavior of turbulence in the vSBL. 
(a)

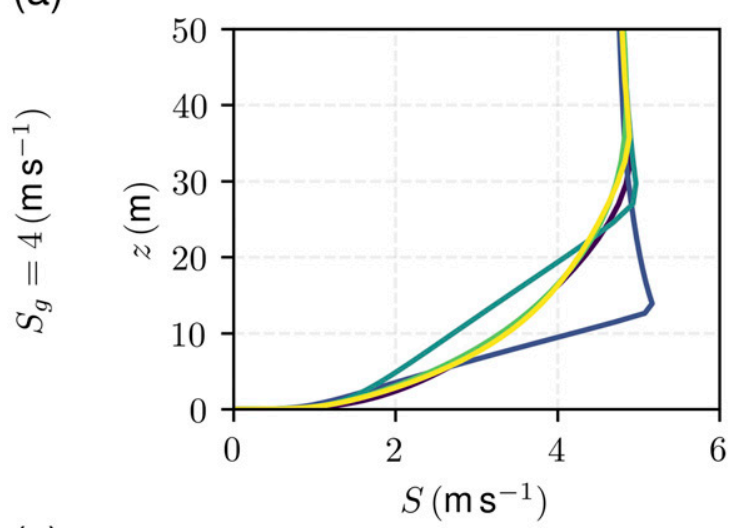

(c)

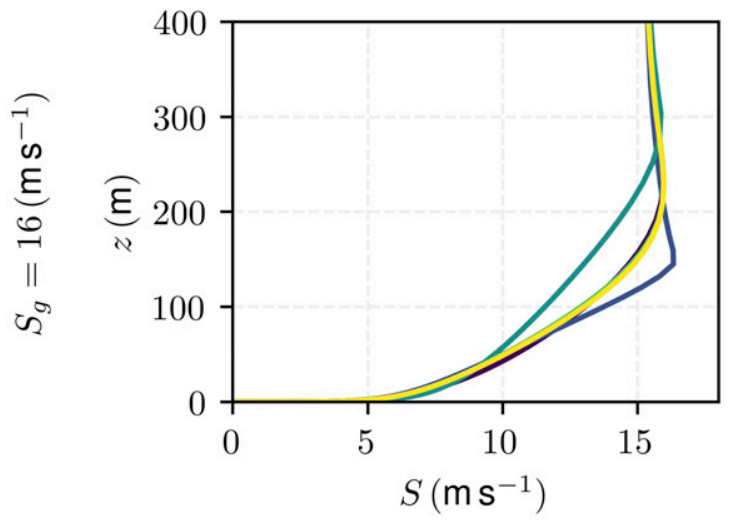

(b)



(d)

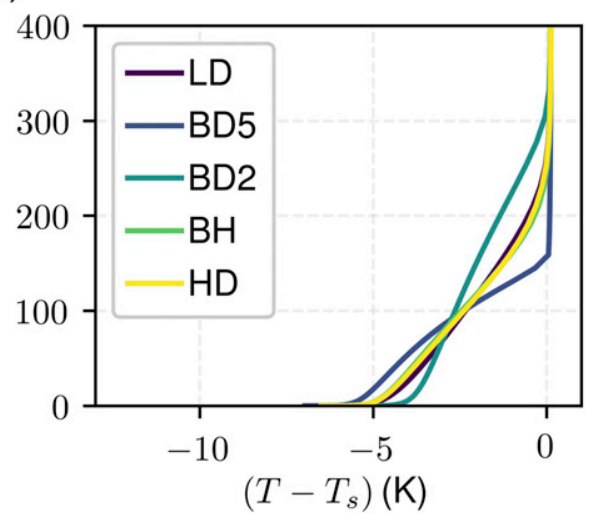

FIG. 5. Vertical profiles of (left) wind speed and (right) temperature for the different stability functions are shown at $t=6 \mathrm{~h}$. Two different wind speed classes are shown representing (a),(b) the vSBL with $S_{g}=4 \mathrm{~m} \mathrm{~s}^{-1}$ and (c),(d) the wSBL with $S_{g}=16 \mathrm{~m} \mathrm{~s}^{-1}$.

Figure 5 shows that $\mathrm{BH}, \mathrm{HD}$, and $\mathrm{LD}$ result in temperature profiles that are more similar near the top of the profile to observations from Cabauw than the BD functions (cf. Fig. 5 of van der Linden et al. 2017). While the wind speed profiles and height of the boundary layer are very similar for $\mathrm{BH}, \mathrm{LD}$, and HD functions, Fig. 4 (first column) and Fig. 5b show that, although all three of these functions exhibit a negative curvature near the surface in the vSBL, the curvature of the HD temperature profile is more pronounced. Negative curvature is observed to be associated with near-surface clear-air radiative cooling in the vSBL (André and Mahrt 1982) and is evident in composite profiles from Cabauw for weak winds in Fig. 3 of Baas et al. (2018). This curvature is consistent with the model results of Edwards (2009a,b) who used a force-restore method with high spatial and high spectral resolution. The HD function is recommended by Andreas (2002) who argued for the existence of a critical Richardson number and turbulent Prandtl number of order one. Based on the strong negative curvature of the temperature profile in the vSBL and similar morphology to the Cabauw profiles, we will use the HD function for the remainder of our analysis.

Figure 6 shows the evolution of various stable boundary layer variables for the control simulation, for a range of different geostrophic wind speeds. The similarity of the modeled friction velocities and surface heat fluxes with observations from Cabauw is remarkable given the simplicity of our model and the biases in the boundary layer structure for weak winds [cf. Fig. 2 of Baas et al. (2018) and Fig. 3 of van der Linden et al. (2017)]. The evolution of $\mathrm{Ri}_{B}$ is shown in Fig. 6a, with the critical value separating the wSBL and $\mathrm{VSBL}$ indicated by a red line. For $S_{g}$ below this line (wSBL) the curves corresponding to equally spaced $S_{g}$ values are more tightly packed than the lines above (vSBL). This fact is particularly noteworthy given the logarithmic scaling of $\mathrm{Ri}_{B}$ in this plot. This difference in behavior motivates the choice of $\mathrm{Ri}_{B}=0.25$ as the wSBL-vSBL threshold since it approximately marks a qualitative change in behavior of the system. Similarly, the temperature gradients, squared friction velocities and heat 
(a)

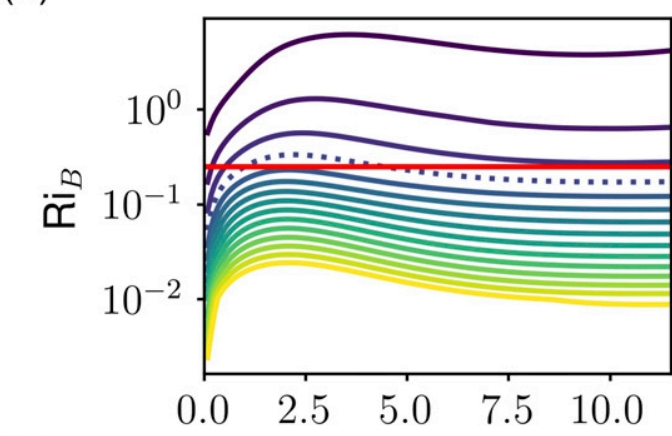

(c)

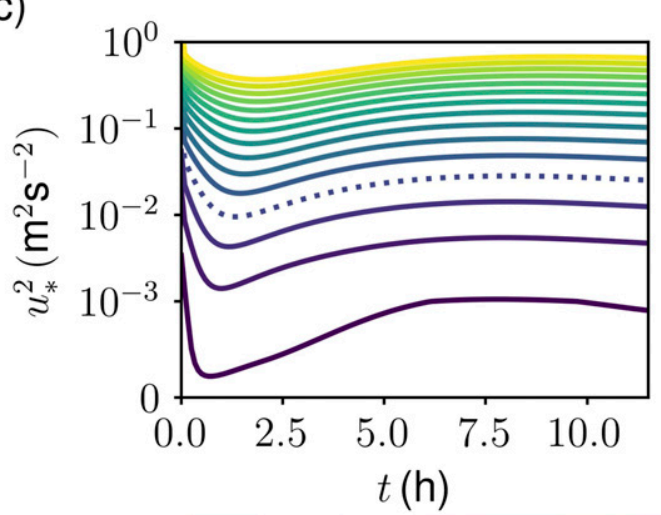

(b)

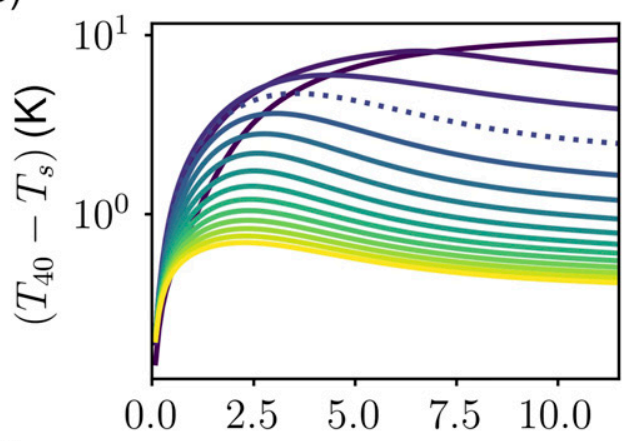

(d)

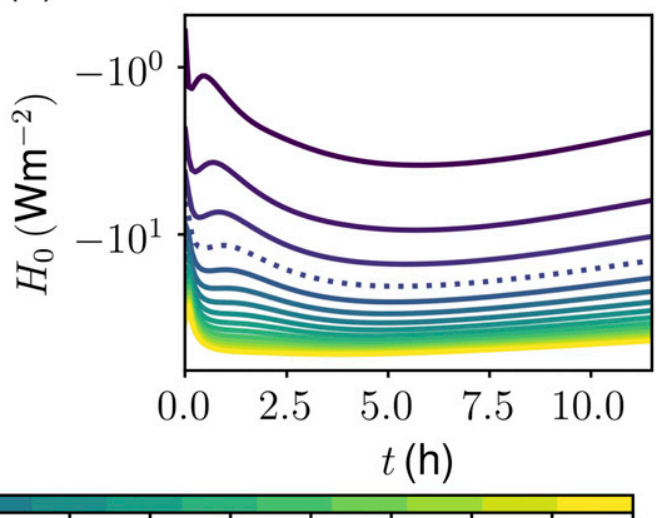

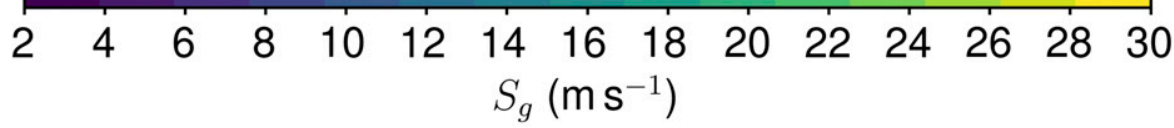

FIG. 6. The evolution of surface characteristics for the control simulations with geostrophic wind speeds in the legend at the bottom: (a) bulk Richardson number, (b) inversion strength at $z=40 \mathrm{~m}$, (c) square of the friction velocity, and (d) turbulent heat flux. The HD stability function is used.

fluxes show a similar pattern of greater variability with $S_{g}$ in the vSBL than in the wSBL (Figs. 6b-d). Only for a relatively narrow range of $S_{g}$ around $8 \mathrm{~m} \mathrm{~s}^{-1}$ (the dashed line Fig. 6) does turbulence collapse and subsequently recover. This result is broadly consistent with the finding in Abraham and Monahan (2019, manuscript submitted to J. Atmos. Sci.) that clear-sky nights remaining within the wSBL or vSBL are approximately separated by a geostrophic wind speed threshold of about $S_{g}=10 \mathrm{~m} \mathrm{~s}^{-1}$. When turbulence collapses in our simulations it occurs rapidly after sunset. The stratification $\left(\mathrm{Ri}_{B}\right)$ that sets in after this initial adjustment remains relatively constant for the remainder of the night. The same is true of the thermal gradient in Fig. 6b which is consistent with observations from Cabauw (cf. Fig. 5 of van der Linden et al. 2017) except when $S_{g}=2 \mathrm{~m} \mathrm{~s}^{-1}$. This discrepancy highlights the well-known difficulty of modeling SBL conditions for weak $S_{g}$. Modeled boundary layer heights are unrealistically shallow for very weak $S_{g}$ so $T_{40}$ is well above $h_{\mathrm{BL}}$. When the gradient is measured from within the boundary layer there is a monotonic increase in the temperature gradients for all $S_{g}$ (not shown).

\section{b. The role of the Coriolis effect}

The idealized model presented here builds on studies of regime shifts in the SBL that have neglected the Coriolis effect in the momentum equation (Van de Wiel et al. 2002a,b, 2007; Holdsworth et al. 2016). The justification for this simplifying assumption is that the time scale of turbulent collapse is much smaller than the time scale of geostrophic adjustment. The validity of this assumption is investigated here by fixing $\partial p / \partial x=\left(10^{-4} \mathrm{~s}^{-1}\right) \rho S_{g}$ using the same discrete range of $S_{g}$ shown in Fig. 6 for simulations with $\left(f_{0}=10^{-4} \mathrm{~s}^{-1}\right)$ and without rotation $\left(f_{0}=0 \mathrm{~s}^{-1}\right)$.

Van de Wiel et al. (2012a) defines the pseudo-steady state (PSS) as the short period of time after the nocturnal transition when the wind and temperature gradients near the surface are relatively stationary, and the time scale of the PSS $t_{\tau_{\min }}$ as the time after sunset when the surface stress reaches a minimum. For nights which 
exhibit a persistent regime over the duration of the night, the regime that will manifest is largely determined over these time scales. The evolution of the wind speed profile toward the PSS for $\partial p / \partial x=0.96 \mathrm{mPa} \mathrm{m}^{-1}$, is shown in Fig. 7a for $f_{0}=0$ and Fig. $7 \mathrm{~d}$ for $f_{0}=10^{-4} \mathrm{~s}^{-1}$. The near-surface profile does not change very much between $t_{\tau_{\min }} / 2$ and $t_{\tau_{\min }}$ for both of the simulations, consistent with the notion of a pseudo-steady state. Even though these time scales are less than the approximate time scale of geostrophic adjustment $\left(2 \pi / f_{0}\right)$, the differences in speed profiles between the rotating and nonrotating simulations indicate that the effect of Coriolis on the evolution of the SBL is quickly evident. Figure $7 \mathrm{~b}$ shows that the time of minimum wind stress occurs later with than without rotation. This result occurs because the downpressure gradient acceleration of the wind is reduced by Coriolis effects so it takes longer for the shear to build up enough to overcome the stabilizing effect of stratification. For larger pressure gradients, $t_{\tau_{\min }}$ increases as a function of $\partial p / \partial x$ for the simulation with rotation, but decreases without rotation. At the beginning of the night, cooling of the surface increases stability and reduces turbulent diffusion. In the absence of rotation, larger pressure gradients drive stronger flows, resulting in more rapid shear-driven turbulence and earlier $t_{\tau_{\min }}$. The situation is more complicated in the presence of rotation as larger pressure gradients drive larger inertial oscillations which result in longer $t_{\tau_{\min }}$.

Some model studies implement a constant speed condition at the upper boundary located at a relatively low altitude within or just above the SBL (McNider et al. 1995; Van de Wiel et al. 2007, 2012b; Acevedo et al. 2012). This boundary condition is justified by appealing to the idea that there exists a crossing point at which the initial wind speed profile $(t=0)$ intersects the profile at $t=t_{\tau_{\min }} / 2$ with speed increasing above and decreasing below. Following Van de Wiel et al. (2012a) we will refer to this as the velocity crossing point. This crossing point (CP) is apparent in both of the simulations (the red crosses in Figs. 7a,d). Figure 7e shows the values of $\mathrm{CP}$ and $h_{\mathrm{BL}} 1 \mathrm{~h}$ after sunset. The rotating simulations exhibit relatively shallow boundary layers since the wind is deflected by the Coriolis effect which reduces the shear. Values of CP are much smaller in the absence of rotation than in its presence. The crossing point is in close agreement with $h_{\mathrm{BL}}$ in the presence of rotation, but the two quantities diverge in the nonrotating case.

Figures $7 \mathrm{c}$ and $7 \mathrm{f}$ show the strength of the temperature inversion $1 \mathrm{~h}$ after sunset, calculated at different fixed heights, as a function of $\partial p / \partial x$. The shape of the curve changes depending on the height at which the inversion strength is calculated. Calculating the inversion strength at a fixed height for all the values of $\partial p / \partial x$ means that for smaller $\partial p / \partial x$ this height is above $h_{\mathrm{BL}}$ and for relatively large $\partial p / \partial x$ it is below $h_{\mathrm{BL}}$ (Fig. 2a). Hence, inversion strength shows a stronger dependence on $\partial p / \partial x$ when the temperature gradient is measured at a fixed height that is nearer to the surface. The relationship between the temperature inversion and the pressure gradient is similar for rotating and nonrotating simulations at the start of the night, but increasingly differs as time goes on (not shown). For sufficiently weak $\partial p / \partial x$ the vSBL persists throughout the night (Figs. 7c,f). Turbulence collapses for stronger $\partial p / \partial x$ in the presence of rotation because Coriolis effects reduce the zonal shear.

To explore the effect of changing the value of the Coriolis parameter $f_{0}$ while keeping the upper boundary conditions the same we fix $S_{g}$ resulting in different values of the horizontal pressure gradient for each $f_{0}$. The wind speed and temperature profiles at $t=6 \mathrm{~h}$ are shown for the vSBL with $S_{g}=4 \mathrm{~m} \mathrm{~s}^{-1}$ (Figs. 8a,b) and for the transition wind speed $S_{g}=8 \mathrm{~m} \mathrm{~s}^{-1}$ (Figs. 8d,e) which exhibits the collapse and recovery of turbulence in our control simulation (Fig. 6). Figures $8 \mathrm{c}$ and $8 \mathrm{f}$ show the wind speed at $z=h_{\mathrm{BL}}$ for these two values of $S_{g}$ normalized by the speed of the geostrophic winds as a function of the inertial period. The wind reaches a maximum supergeostrophic value after $1 / 2$ of an inertial period. For the strongest rotation rates the simulation evolves through nearly one full inertial periods by the end of the night, while for the weakest rotation rates the simulation moves through less than $1 / 4$ of an inertial period. At the fixed time, near-surface winds are stronger for greater rotation rates leading to deeper boundary layers with a more pronounced low-level jet. By construction, simulations with larger rotation rates are associated with larger pressure gradient forces.

The bottom row in Fig. 8 illustrates how the value of $f_{0}$ influences stability and shear as a function of the geostrophic winds. For larger $f_{0}, t_{\tau_{\min }}$ is reached sooner (Fig. 8g). For this plot we omit the case where $f_{0}=2.5 \times 10^{-6} \mathrm{~s}^{-1}$ because the minimum occurs at the end of the night. Stronger rotation rates are associated with larger pressure gradient forces and stronger inertial oscillations so $t_{\tau_{\min }}$ occurs earlier in the night with larger values of the $H_{\max }$ (Fig. 8). Figure 8i shows that, qualitatively, the temperature gradients in the bottom $40 \mathrm{~m}$ of the atmosphere exhibit the same dependence of the stratification on $S_{g}$ that is evident from observations at Cabauw in the Netherlands and Dome $\mathrm{C}$ in Antarctica (Van de Wiel et al. 2017; Vignon et al. 2017; van der Linden et al. 2017; Baas et al. 2018). For stronger $f_{0}$ there is a sharper transition between the wSBL and vSBL. Shear develops more gradually for 


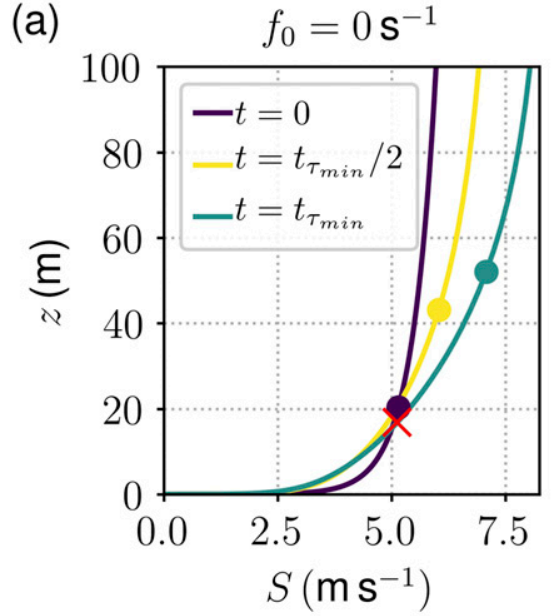

(d)



(b)

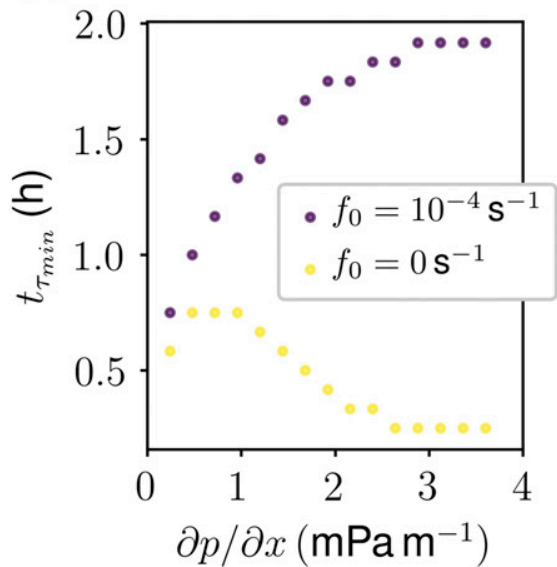

(e)

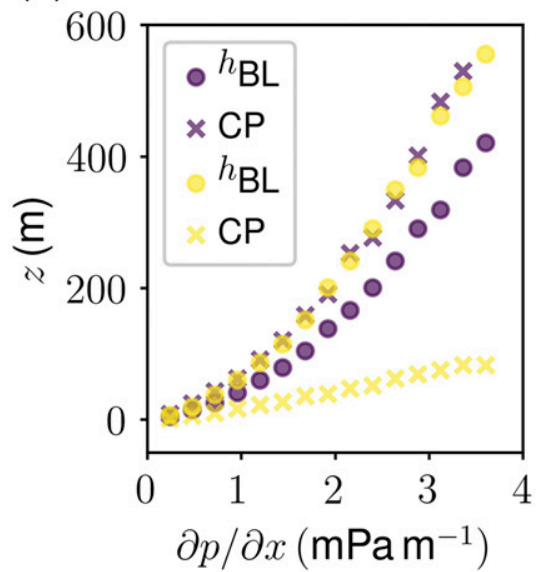

(c)

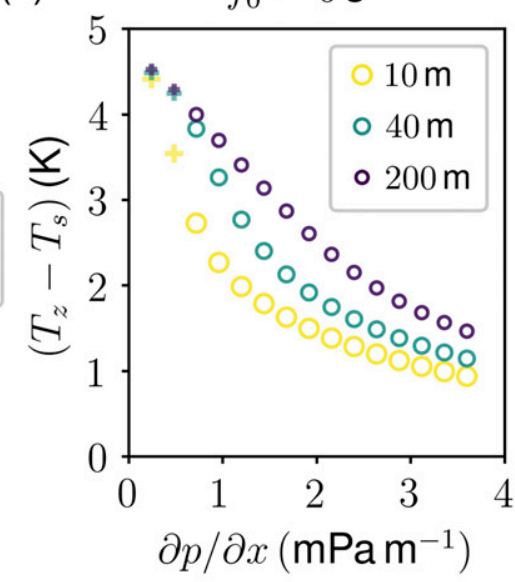

(f)

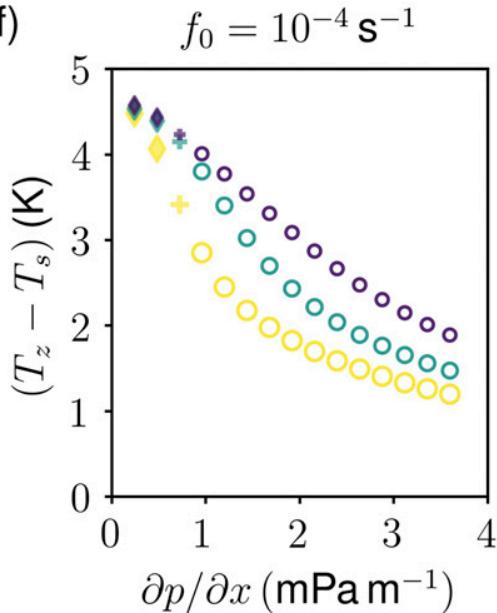

FIG. 7. (left) The evolution of the wind speed profile in the PSS is shown for $\partial p / \partial x=0.96 \mathrm{mPa} \mathrm{m}^{-1}\left(S_{g}=8 \mathrm{~m} \mathrm{~s}^{-1}\right)$ for both (a) nonrotating and (d) rotating simulations. The height of the boundary layer is indicated by a circle for each profile, and the height of the crossing point is indicated by a red cross. (center) For different pressure gradients, (b) the time of the minimum surface stress and (e) the heights are shown. (right) The strength of the temperature gradient was calculated at different heights indicated by the legend for the (c) nonrotating and (f) rotating simulations. The heights and gradients were taken at $t=1 \mathrm{~h}$.

weaker rotation rates resulting in a more prevalent vSBLs that persist throughout the night. For cases where the collapse and recovery of turbulence occurs it is associated with increasing local shear as the wind speed approaches the magnitude of the geostrophic winds.

Gohari and Sarkar (2017) found that turbulent collapse and recovery is influenced by inertial oscillations in their direct numerical simulations. However, it is difficult to directly assess the role of rotation from our analysis because changing $f_{0}$ with $S_{g}$ fixed changes $\partial p / \partial x$, but changing $f_{0}$ with $\partial p / \partial x$ fixed would change $S_{g}$ (and therefore the upper boundary condition).

We find that neglecting rotation is a reasonable assumption when studying the collapse of turbulence for very weak pressure gradients. However it must be noted that there are noticeable effects of Coriolis in the wind and temperature profiles immediately after sunset. In the pseudo-steady state the dependence of inversion strength on the pressure gradient is similar, qualitatively, for both simulations. Over longer time scales, there are more pronounced differences as Coriolis effects reduce local shear affecting both the timing of collapse and the regime occupation.

\section{c. The role of the surface energy budget}

We now investigate how cloud cover, surface type, and subsurface temperature affect the evolution of the SBL for different geostrophic wind speeds. Figure 9 shows the relative contribution of each of the terms in 




(d)

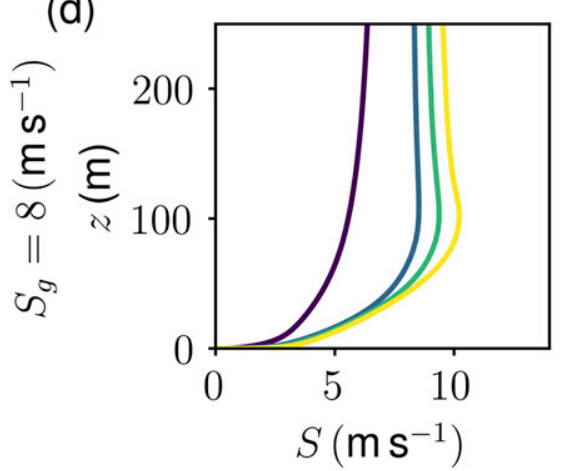

(g)



(b)

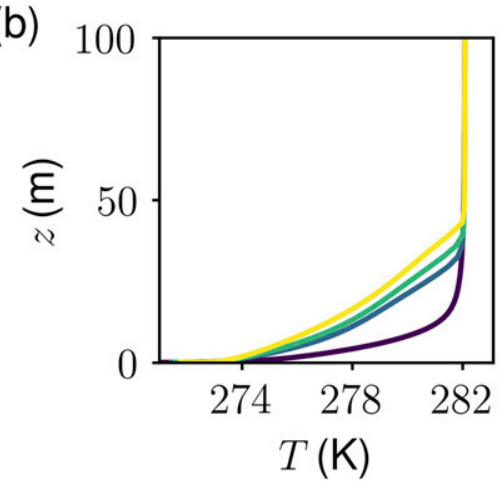

(e)

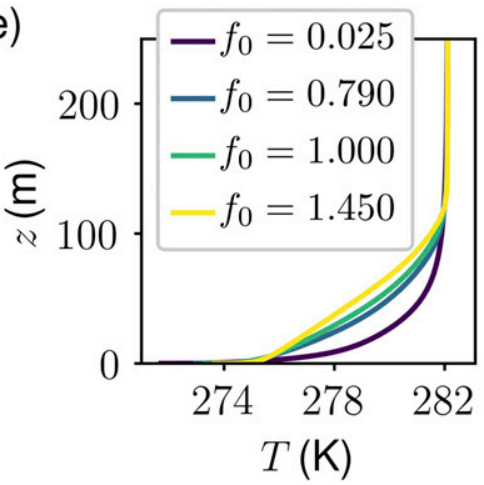

(h)

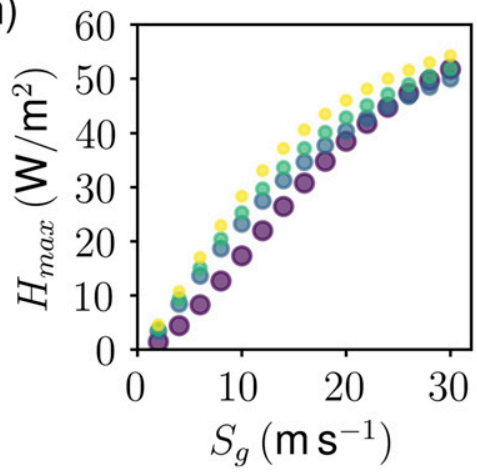

(c)

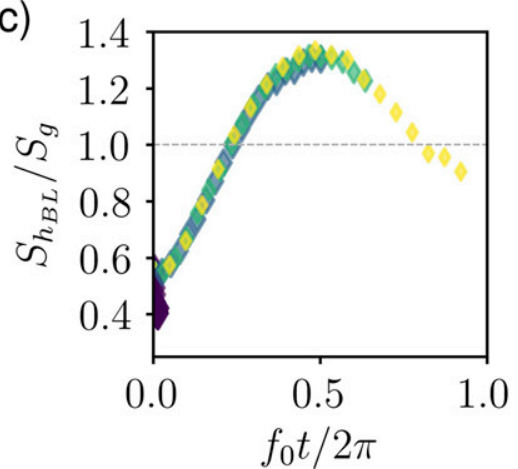

(f)

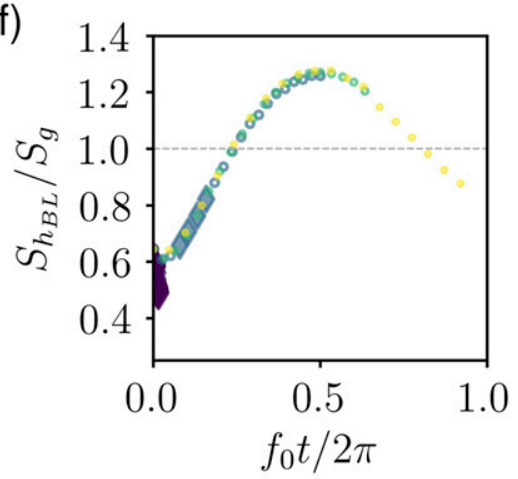

(i)

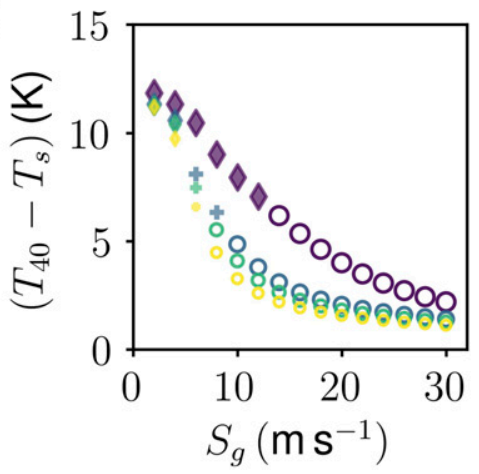

FIG. 8. (a),(d) Profiles of the wind speed and (b),(e) temperature as well as (c),(f) the evolution of the normalized wind speed are shown after $6 \mathrm{~h}$ for (a)-(c) very stable and (d)-(f) transition wind speeds. (g)-(i) Relationship between (g) surface stress, (h) maximum heat flux, and (f) inversion strength and the geostrophic wind. The units of the Coriolis parameter $f_{0}$ in the legend are $10^{-4} \mathrm{~s}^{-1}$.

the energy budget [Eq. (4)] for three values of $S_{g}$ in the control simulation. For each value of $S_{g}$ the radiative cooling term $C_{1} Q_{n}=C_{1}\left(I_{\mathrm{lw}}-\sigma T_{s}^{4}\right)$ dominates the surface energy budget, resulting in an overall surface cooling. Initially, $C_{2} G$ is negative because $T_{s}>T_{d}$ at $t=0$, but it rapidly becomes positive due to the surface cooling. Larger values of $S_{g}$ result in larger contributions of the surface heat flux to the surface temperature tendency and a more rapid equilibration of surface temperature. Furthermore, as $S_{g}$ increases the relative contribution of the subsurface heat flux to the temperature tendency decreases. For $S_{g}=2 \mathrm{~ms}^{-1}$ (a vSBL case), the subsurface heat flux dominates the sensible heat flux. For $S_{g}=8 \mathrm{~m} \mathrm{~s}^{-1}$ (in which turbulence initial collapses but then recovers), the two contributions are approximately equal. Finally, for $S_{g}=16 \mathrm{~m} \mathrm{~s}^{-1}$ (a wSBL case), the subsurface heat flux is much smaller than the sensible heat flux.

Using the Regional Atmospheric Climate Model (RACMO) single-column model to simulate the SBL at Cabauw, Baas et al. (2018) suggested that such differences in the relative importance of sensible heat flux and subsurface heat flux are characteristic features of the vSBL and wSBL. Figure 10 (top row) shows $\mathrm{Ri}_{B}$ as a function of time for three surface types that have similar specific heat capacities, but different thermal 

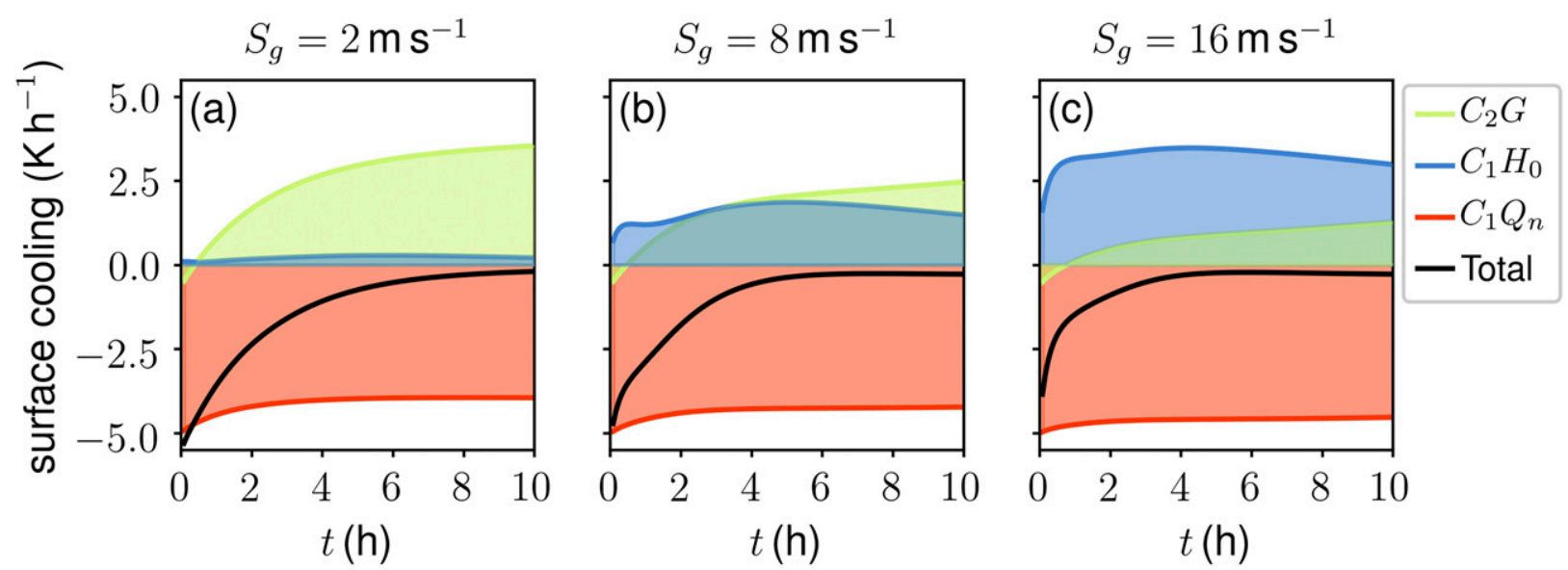

FIG. 9. The evolution of surface energy budget [Eq. (4)] for the control simulation (dry sand) with (a) weak $\left(S_{g}=2 \mathrm{~m} \mathrm{~s}^{-1}\right)$, (b) transition $\left(S_{g}=8 \mathrm{~m} \mathrm{~s}^{-1}\right)$, and (c) strong $\left(S_{g}=16 \mathrm{~m} \mathrm{~s}^{-1}\right)$ geostrophic winds.

conductivities: new snow with $\lambda_{s}=0.08 \mathrm{~W} \mathrm{~m}^{-1} \mathrm{~K}^{-1}$, old snow with $\lambda_{s}=0.42 \mathrm{~W} \mathrm{~m}^{-1} \mathrm{~K}^{-1}$, and ice with $\lambda_{s}=2.24 \mathrm{~W} \mathrm{~m}^{-1} \mathrm{~K}^{-1}$ (Table 2). For a geostrophic wind speed of $S_{g}=8 \mathrm{~m} \mathrm{~s}^{-1}$ (shown with a dotted line), the transition wind speed in the control simulation, the stability regime occupied depends on the thermal conductivity of the surface. For new snow, turbulence collapses within a few hours of sunset and, although $\mathrm{Ri}_{B}$ decreases over the remainder of the night, it does not recover. For old snow, turbulence collapses shortly after sunset and recovers over the next few hours. Plots of $d \mathrm{Ri}_{B} / d t$ show that $\mathrm{Ri}_{B}$ is increasing once more at the end of the night (not shown), potentially leading to another collapse. In contrast, conditions remain weakly stable throughout the night for ice.

The corresponding surface energy budgets for $S_{g}=$ $8 \mathrm{~m} \mathrm{~s}^{-1}$ are shown with solid lines in Figs. 10d-f. The total surface cooling is relatively large for new snow, weaker for old snow, and weaker still for ice. Sensible heat fluxes dominate subsurface heat fluxes in the vSBL new snow simulation (Fig. 10d), while the opposite is true in the wSBL ice simulation (Fig. 10f). This result indicates that the relationship between sensible and subsurface heat fluxes suggested by Baas et al. (2018) is not a generic feature of the distinction between the two SBL regimes. That study concluded that in the vSBL the sensible heat flux constitutes only a small fraction of the surface energy budget. While this is true for our control simulations shown in Fig. 9 (dry sand), the surface budgets shown in Fig. 10 demonstrate that this conclusion is not generalizable. The relative contribution of each term in the surface energy budget is dependent on the properties of the underlying surface.
To further study the role of the subsurface heat flux in the surface energy budget a series of simulations were performed with $C_{2}=0$, suppressing the subsurface heat flux from the budget. The dashed lines in the second row of Fig. 10 indicate the resulting surface energy budget. For new snow, the total surface cooling does not change much when $C_{2}=0$ indicating that in this case energetic coupling to the surface is not a dominant factor influencing turbulent collapse. More pronounced differences in surface cooling are apparent for old snow and ice. Figures $10 \mathrm{~g}-\mathrm{i}$ illustrate the time evolution of $\mathrm{Ri}_{B}$ in the absence of a subsurface heat flux for these cases. For new snow, these curves are not substantially different from those shown in Fig. 10a. In contrast, for old snow turbulence collapses rapidly whether or not a subsurface energy flux is present, but does not recover in the absence of energetic coupling to the surface. Over ice, turbulence does not collapse; however, without the subsurface heat flux $\mathrm{Ri}_{B}$ begins increasing in time after about $6 \mathrm{~h}\left(d \mathrm{Ri}_{B} / d t\right.$ are not shown) potentially leading to turbulent collapse. The feedback associated with the subsurface gradient has little effect on turbulent collapse as it takes some time to adjust to the cooling of the surface, but it appreciably affects turbulent recovery. In addition to influencing the process of turbulent collapse as described in Van de Wiel et al. (2017), feedbacks associated with the subsurface heat flux can affect the process of the turbulent recovery.

Figure 11a shows the strength of the temperature inversion as a function of $S_{g}$ for the range of surface types in Table 2. The size of the marker in Fig. 11a corresponds to the thermal conductivity of the surface. Consistent with the results of Van de Wiel et al. (2017), surfaces with large thermal conductivities such as rock or wet clay are associated with weaker temperature 

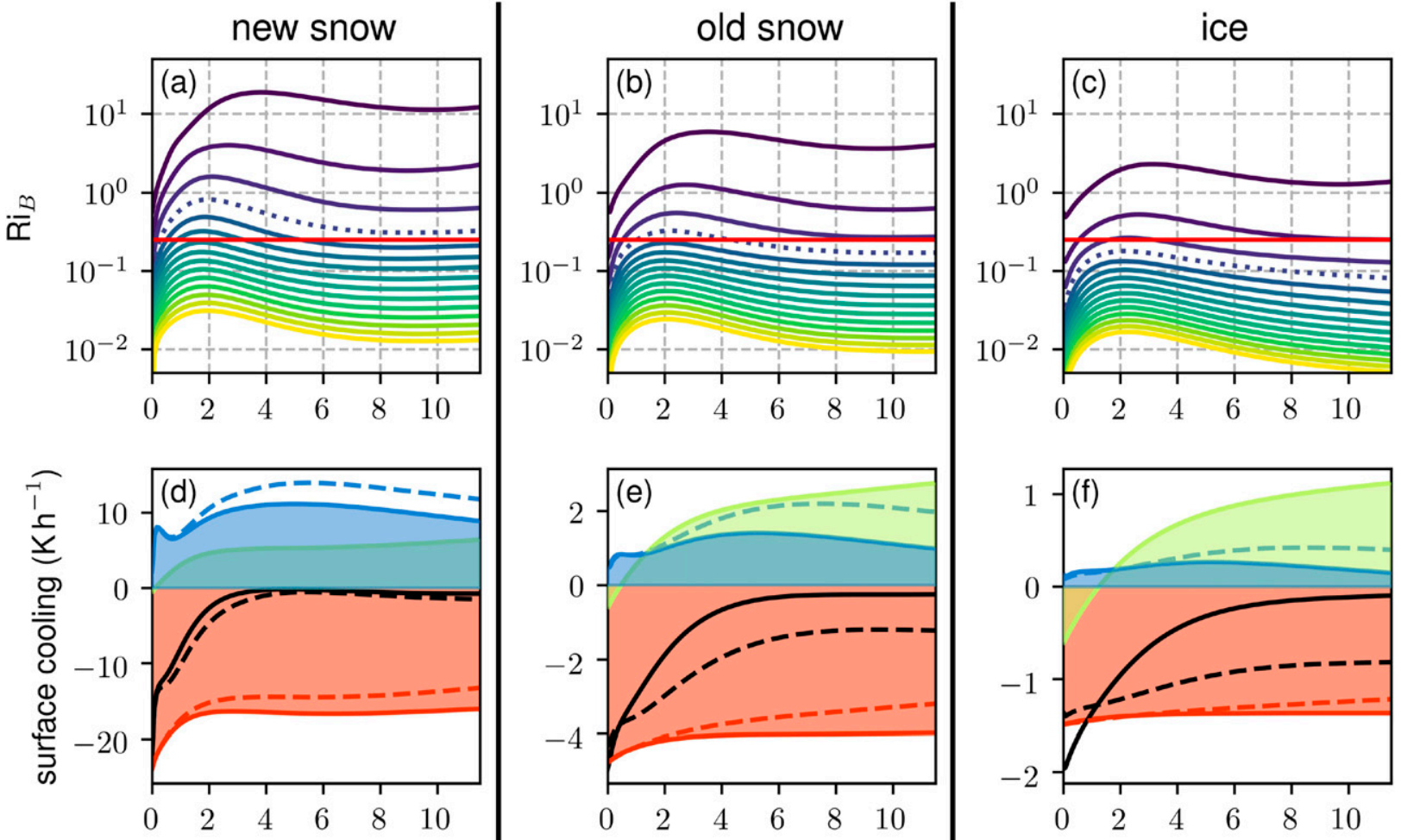
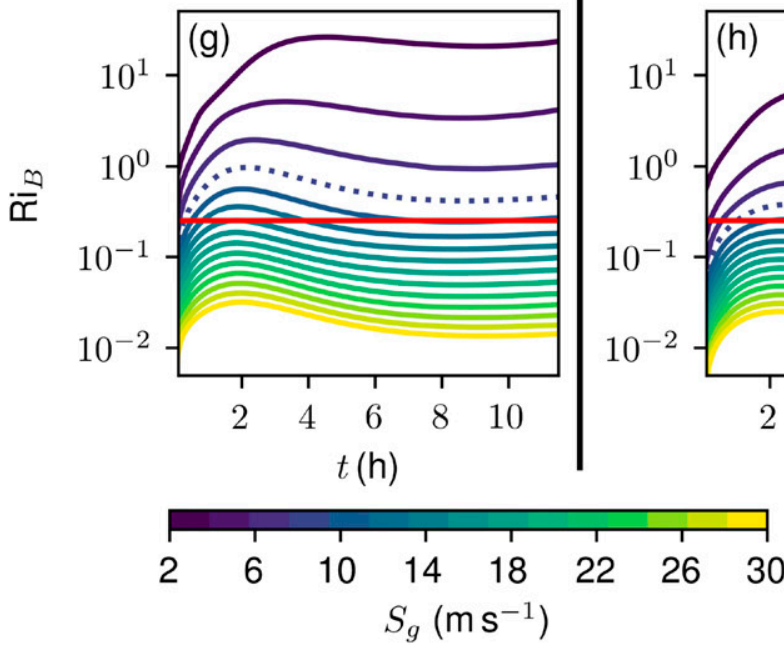
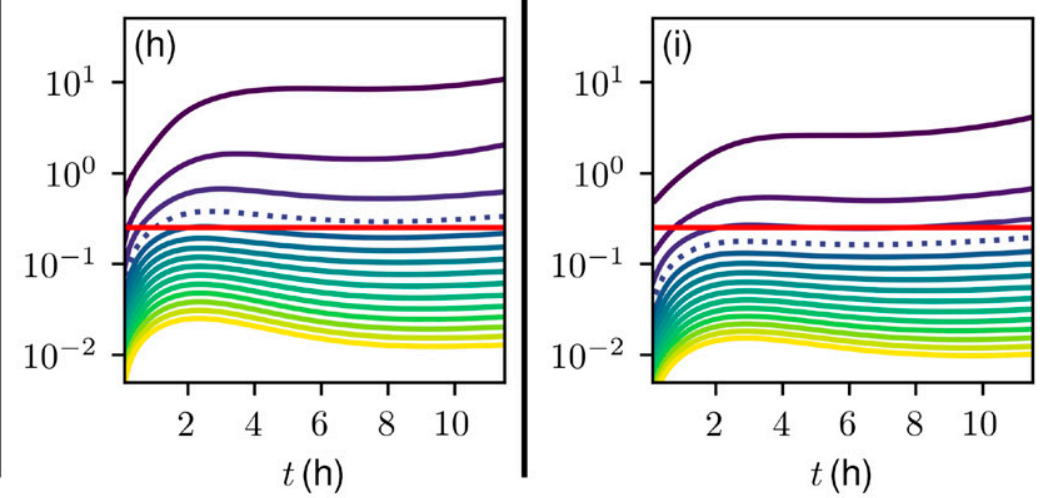

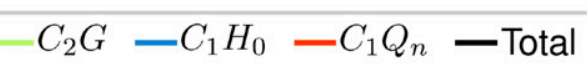

FIG. 10. (left to right) Selected surface types. (a)-(c) Evolution of the bulk Richardson number is shown for different $S_{g}$. The critical value $\mathrm{Ri}_{B}=0.25$ is shown by a solid red line. (d)-(f) Corresponding surface energy budgets for $S_{g}=8 \mathrm{~m} \mathrm{~s}^{-1}$ are shown. The dashed lines show the budgets when $C_{2}=0$. (g)-(i) Evolution of the bulk Richardson number is shown when $C_{2}=0$. Surface properties can be found in Table 2.

gradients and lower sensitivity to $S_{g}$ than surfaces with much smaller thermal conductivities such as new snow and dry clay. For dry sand, the surface type used in our control simulations, the transition wind speeds that separate the vSBL from the wSBL are around $6-8 \mathrm{~m} \mathrm{~s}^{-1}$, while for new snow much greater wind speed is needed to generate enough mixing to sustain the wSBL.
To examine the influence of clouds on static stability, the inversion strength in a series of simulations with different values of cloud cover $Q_{c}$ are investigated (Fig. 11b). For full cloud cover $Q_{c}=1$, the stratification generally remains neutral and in fact becomes unstable (not shown) likely as a result of the initially positive subsurface gradient. During overcast conditions 
(a)

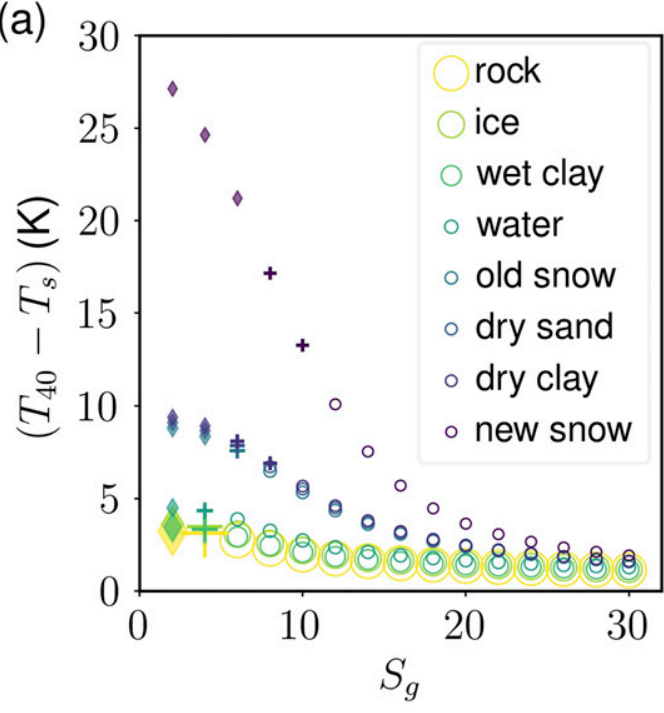

(b)

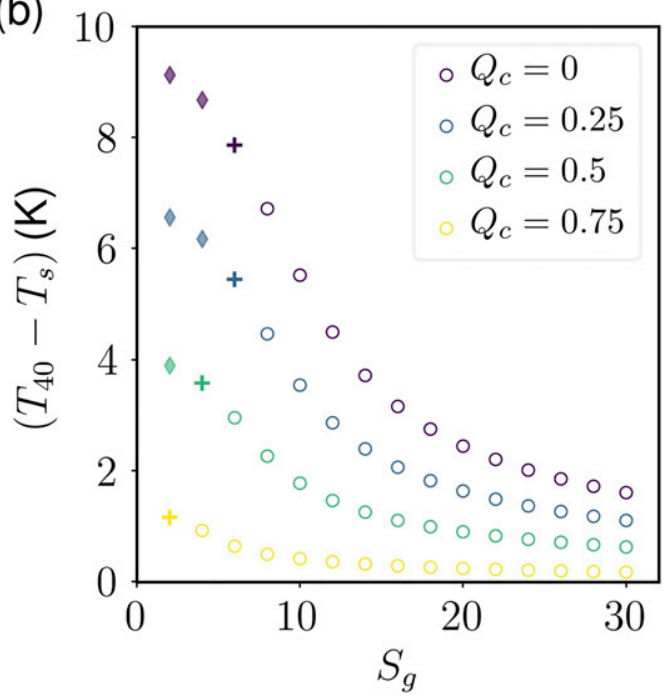

FIG. 11. The strength of the temperature inversion at $3 \mathrm{~h}$ between $z=40 \mathrm{~m}$ and the surface for (a) surface types and (b) cloudiness. In (a) the size of the marker is determined by the thermal conductivities found in Table 2.

$\left(Q_{c}=0.75\right)$ the inversion strengths are relatively weak, while for clear skies $\left(Q_{c}=0\right)$ the inversion is up to $8 \mathrm{~K}$ stronger in the vSBL than in the wSBL. Unsurprisingly, the value of $S_{g}$ separating the wSBL from the vSBL depends on $Q_{c}$. Although this effect is relatively small, for clear skies $\left(Q_{c}=0\right)$ larger geostrophic wind speeds are needed to generate enough mixing to overcome the strong radiative cooling of the surface and sustain the wSBL. In agreement with a statistical analysis of tower data from Cabauw (Monahan et al. 2015), we find that wSBL occupation is favored by larger geostrophic wind speed and cloud cover.

For different amounts of cloud cover Figs. 12a-c show the variation in $\mathrm{Ri}_{B}$ with $S_{g}$ for the surface parameters of the control simulation. These panels demonstrate that the cloud cover influences both the collapse and recovery of turbulence in the SBL. The corresponding energy budgets (Figs. 12d,e,f) are shown for $S_{g}=6 \mathrm{~m} \mathrm{~s}^{-1}$, for which the collapse of turbulence depends on $Q_{c}$. The magnitude of the total surface cooling decreases with increasing $Q_{c}$ due to the increase in longwave radiation at the surface. There is a similar variation in the turbulent sensible heat flux and considerable variation of the subsurface gradient with $Q_{c}$. During overcast conditions radiative cooling occurs slowly enough that the subsurface gradient supplies enough energy to the surface to prevent turbulent collapse for all but the smallest geostrophic wind speeds. Again we see an example of a wSBL night in which the subsurface heat flux is an important part of the surface energy budget.
Finally, to explore the influence of the subsurface temperature a series of simulations are shown for different values of $T_{d}$. When $T_{d}=283 \mathrm{~K}$ the initial temperature at the lowest model level is equivalent to the surface temperature at sunset $T_{d}(0)=T_{s}(0)$. Typical winter conditions have $T_{s}(0)<T_{d}(0)$ while in the summertime $T_{s}(0)>T_{d}(0)$. Figure 13a shows that the inversion strengths depend on the subsurface temperature. For $S_{g}=8 \mathrm{~m} \mathrm{~s}^{-1}$ turbulence collapses if the subsurface temperature is sufficiently cold relative to the surface $(\simeq 4 \mathrm{~K}$ cooler $)$. When $T_{d}(0)=279 \mathrm{~K}$ turbulence collapses about an hour after the start of the simulation and recovers over the next couple of hours (Fig. 13b). Turbulence nearly collapses for $T_{d}(0)=281 \mathrm{~K}$ as well, but the near-surface cooling is not as strong (Fig. 13c) so the subsurface gradient grows quickly enough to compensate (Fig. 13d) and stability decreases.

\section{Discussion}

Our idealized model demonstrates that the most commonly used parameterizations of turbulence are able to simulate both the collapse and recovery of turbulence in the vSBL in the presence of a large-scale horizontal pressure gradient, Coriolis effects, and a surface energy budget. Because of the simplicity of the model and the neglect of processes such as intermittent turbulence in the vSBL, the timing and magnitudes of changes across transitions may not be accurately represented. While in this study we often compare our results to observations at Cabauw, we do not attempt to replicate observations at any particular site 

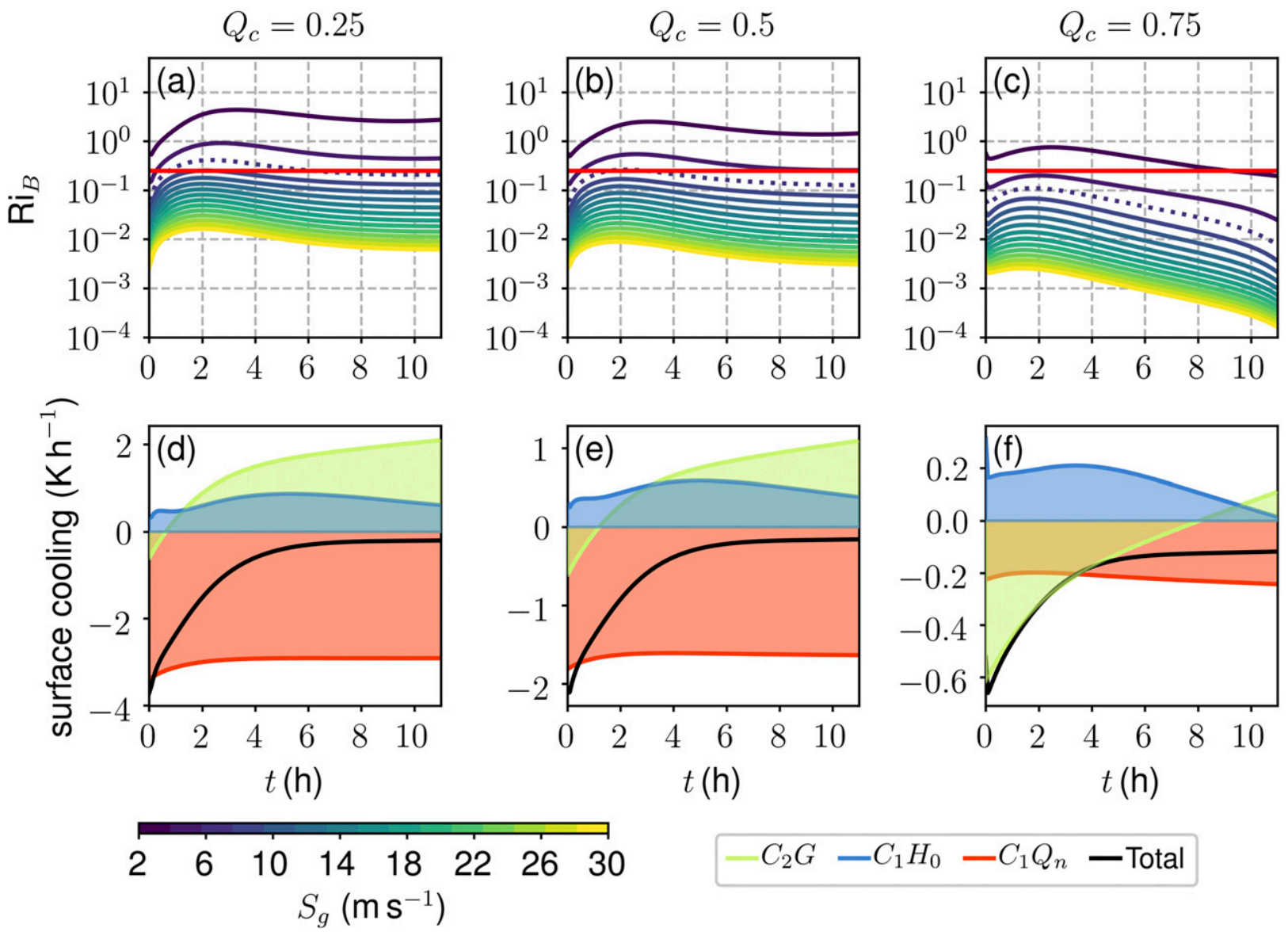

FIG. 12. The evolution of (a)-(c) the bulk Richardson number and (d)-(f) surface cooling budget [Eq. (4)] for the control simulation under varying amounts of cloud cover.

exactly. Closer matches between the model and any specific set of observations could use site-specific initial conditions and surface characteristics or a more sophisticated model of the surface energy budget. Furthermore, more complicated parameterizations of turbulence could be considered including for example more detailed treatments of the mixing length or adding a turbulent Prandtl number (He et al. 2019). We do find that the representation of the vSBL in our model for very weak geostrophic winds exhibits boundary layers which are too shallow. The representation of the stable boundary layer under very stable conditions remains a challenge to NWP and climate models.

Our results have illustrated how enhanced mixing from the buildup of shear and subsurface heat flux feedbacks can drive the recovery of turbulence. Further study is needed to understand the role that other neglected processes such as density-driven currents, solitary waves, and internal gravity waves (Sun et al. $2002,2004)$ play in regime transitions and to represent them in NWP and climate models. A good starting point for such a study would be to represent these processes in idealized models like the one presented here.

Related idealized model studies with much coarser vertical resolution reported abrupt shifts between regimes (limit cycle behavior) (Van de Wiel et al. 2002b; ReVelle 1993; McNider et al. 1995) not found in this much higher-resolution model. In fact, the near-surface resolution we consider is much finer than is used by operational models. For wind speeds that are characteristic of the very stable regime the height of the boundary layer is on the order of a few tens of meters (Fig. 6b) which is too shallow to be resolved by standard NWP and climate models. Changes to the vertical resolution in such models is a significant undertaking because many of the model parameterizations are tuned to the existing resolution. Nevertheless, studies show that poor vertical resolution in the SBL can lead to large errors in the radiative flux (Räisänen 1996) and may be essential to preventing the surface warm bias (McNider et al. 2012). More work is needed to determine if an increase in model resolution is necessary to capture the effects of these near-surface dynamics. 
(a)

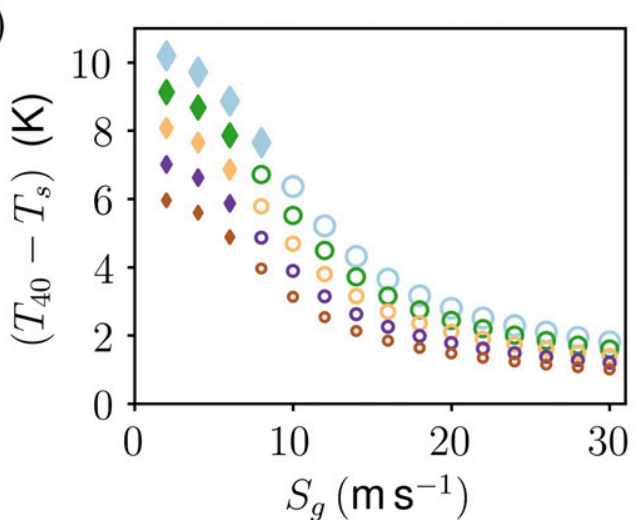

(c)

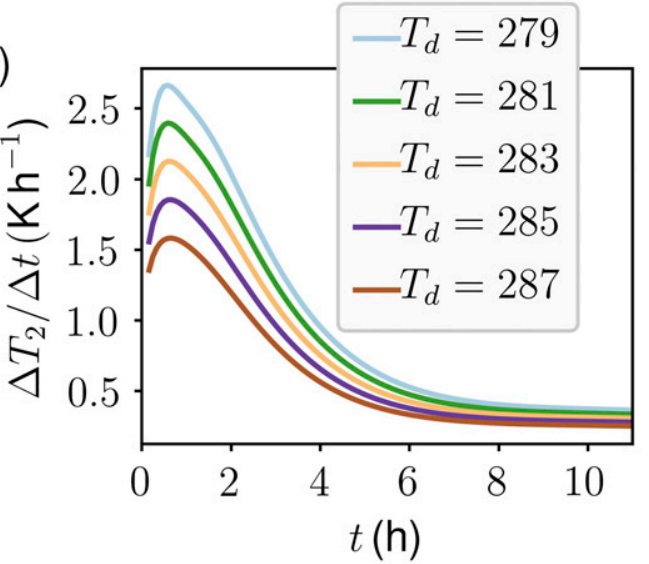

(b)

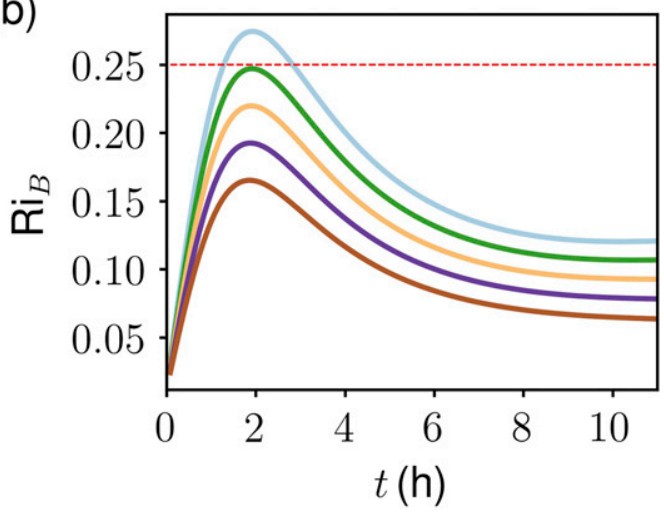

(d)

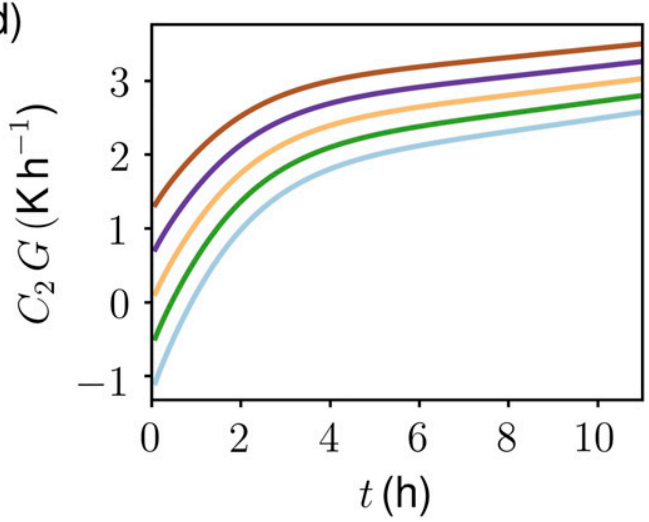

FIG. 13. For different subsurface temperatures, (a) the temperature inversion is shown as a function of the geostrophic wind. When $S_{g}=8 \mathrm{~m} \mathrm{~s}^{-1}$, (b) the bulk Richardson number, (c) the rate of cooling $\Delta T / \Delta t(z=2 \mathrm{~m})$, and (d) subsurface energy flux are shown for different values of the subsurface temperature (K).

The above analysis considered the influence of the geostrophic winds, cloud cover, thermal conductivity, and the subsurface temperature on regime transitions in the SBL. These quantities were held constant over the duration of the night in our simulations. In the real atmosphere, these forcings all evolve in time, adding another layer of complexity to the dynamics. Moreover, the representation of clouds in our model is rather simplistic and it would be interesting to see how the type of clouds or their location in the atmosphere might affect SBL dynamics.

Our simulations are restricted to a particular set of initial conditions. Preliminary investigations of the onset of the SBL indicate that the system may be sensitive to the atmospheric conditions around sunset (van Hooijdonk et al. 2017). More research is needed to explore the influence of realistic initial conditions on this complex dynamical system.

\section{Conclusions}

This study examined the influence of the large-scale horizontal pressure gradient on conditions of stratification in the SBL using an idealized single-column model with parameterized turbulence and a force-restore surface radiative scheme. A range of stability functions were considered, all of which were capable of qualitatively representing the vertical wind and temperature profiles from the Cabauw tower (van der Linden et al. 2017; Baas et al. 2018; Van de Wiel et al. 2017; Vignon et al. 2017), but there were some quantitative differences. We found that the Holtslag and De Bruin (1988) stability function resulted in shapes of profiles that matched most closely with the observations.

The idealized SCM model showed that the parameterizations of turbulence used in operational models are capable of representing the collapse and recovery of turbulence when coupled with a surface energy budget. This result does not of course indicate that the simulation of either collapse or recovery is quantitatively accurate. For very weak winds the model exhibits relatively shallow boundary layers compared with the observations.

Simulations were performed with and without rotation for a fixed pressure gradient force. Although differences in the wind speed and temperature were apparent 
between the rotating and nonrotating cases at the start of the simulation, the two simulations exhibited similar trends in atmospheric stability. Simulations with $f=0$ exhibit more rapid turbulent collapse and deeper boundary layers. Simulations performed with variable $f_{0}$ and fixed $S_{g}$ indicate that when the inertial period is short compared to the length of the night, inertial oscillations are associated with a vSBL-wSBL transition. Further study is needed to determine whether inertial oscillations are actually the cause of this transition.

In agreement with observations (Monahan et al. 2015; van der Linden et al. 2017; Baas et al. 2018), we found that the strength of the large-scale pressure gradient strongly influences regime occupation in the SBL because the it controls the amount of turbulent mixing near the surface. The regime occupied by the SBL for a given geostrophic wind speed depends on the ambient cloud cover, the thermal conductivity of the surface, and the temperature of the subsurface through their influence on the surface energy budget (as in Van de Wiel et al. 2017). Cloud cover affects the amount of downwelling longwave radiation making wSBLs more likely for increasing cloud cover. Surfaces with larger thermal conductivities transfer heat more efficiently from the subsurface to the surface and relatively warm subsurface temperatures increase the subsurface gradient.

Occupation of either the weakly stable or very stable regimes is not simply a tug of war between the surface radiative cooling and the downward transport of turbulence controlled by the geostrophic winds. Rather it is the combined effect of the rate of heat transport from the subsurface together with the turbulent transport of heat from above that counters the radiative cooling of the surface (although, in contrast with the findings of previous studies, the occupied regime is not simply determined by the relative magnitude of the sensible and subsurface heat fluxes). Moreover, the relative importance of these terms is found to depend strongly on the thermal conductivity of the surface and the ambient cloud cover and weakly on the temperature of the subsurface. The idealized SCM shows that the subsurface can play an important role in the vSBL-wSBL transition depending on the thermal conductivity. The influence of cloud cover is more pronounced affecting both the collapse and recovery of turbulence.

Acknowledgments. The authors sincerely thank Otávio Acevedo and two anonymous reviewers whose suggestions have improved the quality of the manuscript. Thanks to Carsten Abraham, Ivo van Hooijdonk, and Bas van de Wiel for useful discussions about our work. We acknowledge support by the Natural Sciences and Engineering Research Council of Canada (NSERC).

\section{REFERENCES}

Acevedo, O. C., F. D. Costa, and G. A. Degrazia, 2012: The coupling state of an idealized stable boundary layer. Bound.-Layer Meteor., 145, 211-228, https://doi.org/10.1007/s10546-011-9676-3.

André, J. C., and L. Mahrt, 1982: The nocturnal surface inversion and influence of clear-air radiative cooling. J. Atmos. Sci., 39, 864-878, https://doi.org/10.1175/1520-0469(1982)039<0864: TNSIAI $>2.0 . \mathrm{CO} ; 2$

Andreas, E. L., 2002: Parameterizing scalar transfer over snow and ice: A review. J. Hydrometeor., 3, 417-432, https://doi.org/ 10.1175/1525-7541(2002)003<0417:PSTOSA > 2.0.CO;2.

Arya, S. P., 1999: Air Pollution Meteorology and Dispersion. Oxford University Press, $310 \mathrm{pp}$.

Baas, P., B. J. H. van de Wiel, S. J. A. van der Linden, and F. C. Bosveld, 2018: From near-neutral to strongly stratified: Adequately modelling the clear-sky nocturnal boundary layer at Cabauw. Bound.-Layer Meteor., 166, 217-238, https://doi.org/10.1007/s10546-017-0304-8.

Banta, R. M., L. Mahrt, D. Vickers, J. Sun, B. B. Balsley, Y. L. Pichugina, and E. J. Williams, 2007: The very stable boundary layer on nights with weak low-level jets. J. Atmos. Sci., 64, 3068-3090, https://doi.org/10.1175/JAS4002.1.

Beljaars, A. C. M., and A. A. M. Holtslag, 1991: Flux parameterization over land surfaces for atmospheric models. J. Appl. Meteor., 30, 327-341, https://doi.org/10.1175/1520-0450(1991) $030<0327$ :FPOLSF $>2.0$. CO;2.

Blackadar, A. K., 1962: The vertical distribution of wind and turbulent exchange in a neutral atmosphere. J. Geophys. Res., 67, 3095-3102, https://doi.org/10.1029/JZ067i008p03095.

- 1976: Modeling the nocturnal boundary layer. Proc. Third Symp. on Atmospheric Turbulence, Diffusion and Air Quality, Boston, MA, Amer. Meteor. Soc., 46-49.

1979: High resolution models of the planetary boundary layer. Adv. Environ. Sci. Eng., 1, 50-85.

Bosveld, F. C., 2018: Cabauw reference site. UCAR, accessed 30 June 2018, https://www.eol.ucar.edu/projects/ceop/dm/insitu/ sites/baltex/cabauw/cabauw/.

, and Coauthors, 2014: The third GABLS intercomparison case for evaluation studies of boundary-layer models. Part B: Results and process understanding. Bound.-Layer Meteor., 152, 157-187, https://doi.org/10.1007/s10546-014-9919-1.

Brown, A., R. Beare, J. Edwards, A. Lock, S. Keogh, S. Milton, and D. Walters, 2008: Upgrades to the boundary-layer scheme in the Met Office numerical weather prediction model. Bound.-Layer Meteor., 128, 117-132, https://doi.org/10.1007/s10546-008-9275-0.

Businger, J. A., 1973: Turbulent transfer in the atmospheric surface layer. Workshop on Micrometeorology, D. A. Haugen, Ed., Amer. Meteor. Soc., 67-100.

- 1988: A note on the Businger-Dyer profiles. Bound.-Layer Meteor., 42, 145-151, https://doi.org/10.1007/BF00119880.

— J. J. Wyngaard, Y. Izumi, and E. F. Bradley, 1971: Flux-profile relationships in the atmospheric surface layer. J. Atmos. Sci., 28, 181-189, https://doi.org/10.1175/1520-0469(1971)028<0181: FPRITA $>2.0 . \mathrm{CO} ; 2$.

Carson, D., and P. Richards, 1978: Modelling surface turbulent fluxes in stable conditions. Bound.-Layer Meteor., 14, 67-81, https://doi.org/10.1007/BF00123990.

Chenge, Y., and W. Brutsaert, 2005: Flux-profile relationships for wind speed and temperature in the stable atmospheric boundary layer. Bound.-Layer Meteor., 114, 519-538, https://doi.org/ 10.1007/s10546-004-1425-4.

Clarke, R., 1970: Observational studies in the atmospheric boundary layer. Quart. J. Roy. Meteor. Soc., 96, 91-114, https://doi.org/ 10.1002/qj.49709640709. 
Deardorff, J. W., 1978: Efficient prediction of ground surface temperature and moisture, with inclusion of a layer of vegetation.J. Geophys. Res., 83, 1889-1903, https://doi.org/10.1029/ JC083iC04p01889.

Delage, Y., 1997: Parameterising sub-grid scale vertical transport in atmospheric models under statically stable conditions. Bound.-Layer Meteor., 82, 23-48, https://doi.org/10.1023/ A:1000132524077.

Derbyshire, S., 1999: Boundary-layer decoupling over cold surfaces as a physical boundary-instability. Bound.-Layer Meteor., 90, 297-325, https://doi.org/10.1023/A:1001710014316.

Dyer, A., 1974: A review of flux-profile relationships. Bound.-Layer Meteor., 7, 363-372, https://doi.org/10.1007/BF00240838.

ECMWF, 2013: IFS documentation-Cy40r1: Part IV: Physical processes. European Centre for Medium-Range Weather Forecasts Rep., 190 pp.

Edwards, J., 2009a: Radiative processes in the stable boundary layer: Part I. Radiative aspects. Bound.-Layer Meteor., 131, 105-126, https://doi.org/10.1007/s10546-009-9364-8.

_ 2009 b: Radiative processes in the stable boundary layer: Part II. The development of the nocturnal boundary layer. Bound.-Layer Meteor., 131, 127-146, https://doi.org/10.1007/ s10546-009-9363-9.

Gohari, S. M. I., and S. Sarkar, 2017: Direct numerical simulation of turbulence collapse and rebirth in stably stratified Ekman flow. Bound.-Layer Meteor., 162, 401-426, https://doi.org/ 10.1007/s10546-016-0206-1.

Grachev, A. A., E. L. Andreas, C. W. Fairall, P. S. Guest, and P. O. G. Persson, 2013: The critical Richardson number and limits of applicability of local similarity theory in the stable boundary layer. Bound.-Layer Meteor., 147, 51-82, https://doi.org/10.1007/ s10546-012-9771-0.

He, Y., N. A. McFarlane, and A. H. Monahan, 2019: A new TKE based parameterization of atmospheric turbulence in the Canadian global and regional climate models. J. Adv. Model. Earth Syst., https://doi.org/10.1029/2018MS001532, in press.

Hicks, B. B., 1976: Wind profile relationships from the "Wangara" experiment. Quart. J. Roy. Meteor. Soc., 102, 535-551, https:// doi.org/10.1002/qj.49710243304.

Holdsworth, A. M., T. Rees, and A. H. Monahan, 2016: Parameterization sensitivity and instability characteristics of the maximum sustainable heat flux framework for predicting turbulent collapse. J. Atmos. Sci., 73, 3527-3540, https://doi.org/10.1175/ JAS-D-16-0057.1.

Holtslag, A., and H. De Bruin, 1988: Applied modeling of the nighttime surface energy balance over land. J. Appl. Meteor., 27, 689-704, https://doi.org/10.1175/1520-0450(1988)027<0689: AMOTNS $>2.0 . \mathrm{CO} ; 2$.

— transformation model for short-range weather forecasting. Mon. Wea. Rev., 118, 1561-1575, https://doi.org/10.1175/ 1520-0493(1990)118<1561:AHRAMT>2.0.CO;2.

- - G. Steeneveld, and B. Van de Wiel, 2007: Role of landsurface temperature feedback on model performance for the stable boundary layer. Atmospheric Boundary Layers, Springer, 205-220.

—_, and Coauthors, 2013: Stable atmospheric boundary layers and diurnal cycles: Challenges for weather and climate models. Bull. Amer. Meteor. Soc., 94, 1691-1706, https://doi.org/10.1175/ BAMS-D-11-00187.1.

Howell, J., and J. Sun, 1999: Surface-layer fluxes in stable conditions. Bound.-Layer Meteor., 90, 495-520, https://doi.org/10.1023/ A:1001788515355.
Kundu, P. K., I. M. Cohen, and D. R. Dowling, 1990: Fluid Mechanics. Academic Press, 638 pp.

Louis, J.-F., 1979: A parametric model of vertical eddy fluxes in the atmosphere. Bound.-Layer Meteor., 17, 187-202, https://doi.org/ 10.1007/BF00117978.

Mahrt, L., 1981: Modelling the depth of the stable boundarylayer. Bound.-Layer Meteor., 21, 3-19, https://doi.org/10.1007/ BF00119363.

_ 1985: Vertical structure and turbulence in the very stable boundary layer. J. Atmos. Sci., 42, 2333-2349, https://doi.org/ 10.1175/1520-0469(1985)042<2333:VSATIT >2.0.CO;2.

_ 1998: Nocturnal boundary-layer regimes. Bound.-Layer Meteor., 88, 255-278, https://doi.org/10.1023/A:1001171313493.

_ 2011: The near-calm stable boundary layer. Bound.-Layer Meteor., 140, 343-360, https://doi.org/10.1007/s10546-011-9616-2.

—_, 2014: Stably stratified atmospheric boundary layers. Annu. Rev. Fluid Mech., 46, 23-45, https://doi.org/10.1146/ annurev-fluid-010313-141354.

__, J. Sun, and D. Stauffer, 2015: Dependence of turbulent velocities on wind speed and stratification. Bound.-Layer Meteor., 155, 55-71, https://doi.org/10.1007/s10546-014-9992-5.

Maroneze, R., O. C. Acevedo, F. D. Costa, and J. Sun, 2019: Simulating the regime transition of the stable boundary layer using different simplified models. Bound.-Layer Meteor., 170, 305-321, https://doi.org/10.1007/s10546-018-0401-3.

McNider, R. T., D. E. England, M. J. Friedman, and X. Shi, 1995: Predictability of the stable atmospheric boundary layer. J. Atmos. Sci., 52, 1602-1614, https://doi.org/10.1175/1520-0469(1995) $052<1602:$ POTSAB $>2.0$. CO;2.

— turnal boundary layer over land to added longwave radiative forcing. J. Geophys. Res., 117, D14106, https://doi.org/10.1029/ 2012JD017578.

McVehil, G. E., 1964: Wind and temperature profiles near the ground in stable stratification. Quart. J. Roy. Meteor. Soc., 90 , 136-146, https://doi.org/10.1002/qj.49709038403.

Moene, A. F., B. J. H. Van de Wiel, and H. J. J. Jonker, 2010: Local similarity profiles from direct numerical simulation. 19th Symp. on Boundary Layers and Turbulence, Keystone, CO, Amer. Meteor. Soc., 3A.2, https://ams.confex.com/ams/ 19Ag19BLT9Urban/webprogram/Paper172247.html.

Monahan, A. H., T. Rees, Y. He, and N. McFarlane, 2015: Multiple regimes of wind, stratification, and turbulence in the stable boundary layer. J. Atmos. Sci., 72, 3178-3198, https://doi.org/ 10.1175/JAS-D-14-0311.1.

Monin, A., and A. Obukhov, 1954: Basic laws of turbulent mixing in the surface layer of the atmosphere. Contrib. Geophys. Inst. Acad. Sci. USSR, 151, 163-187.

Nappo, C. J., 1991: Sporadic breakdowns of stability in the PBL over simple and complex terrain. Bound.-Layer Meteor., 54, 69-87, https://doi.org/10.1007/BF00119413.

Nieuwstadt, F. T. M., 1984: The turbulent structure of the stable, nocturnal boundary layer. J. Atmos. Sci., 41, 2202-2216, https://doi.org/10.1175/1520-0469(1984)041<2202:TTSOTS> 2.0.CO;2.

Pahlow, M., M. B. Parlange, and F. Porté-Agel, 2001: On MoninObukhov similarity in the stable atmospheric boundary layer. Bound.-Layer Meteor., 99, 225-248, https://doi.org/10.1023/ A:1018909000098.

Petersen, E. L., N. G. Mortensen, L. Landberg, J. Højstrup, and H. P. Frank, 1998: Wind power meteorology. Part I: Climate and turbulence. Wind Energy, 1, 25-45, https://doi.org/10.1002/ (SICI)1099-1824(199809)1:1<2::AID-WE15>3.0.CO;2-Y. 
Pruitt, W., D. Morgan, and F. Lourence, 1973: Momentum and mass transfers in the surface boundary layer. Quart. J. Roy. Meteor. Soc., 99, 370-386, https://doi.org/10.1002/qj.49709942014.

Räisänen, P., 1996: The effect of vertical resolution on clear-sky radiation calculations: Tests with two schemes. Tellus, $\mathbf{4 8 A}$, 403-423, https://doi.org/10.3402/tellusa.v48i3.12068.

ReVelle, D. O., 1993: Chaos and "bursting" in the planetary boundary layer. J. Appl. Meteor., 32, 1169-1180, https://doi.org/10.1175/ 1520-0450(1993)032<1169:CAITPB > 2.0.CO;2.

Russell, E. S., H. Liu, Z. Gao, B. Lamb, and N. Wagenbrenner, 2016: Turbulence dependence on winds and stability in a weak-wind canopy sublayer over complex terrain. J. Geophys. Res. Atmos., 121, 11 502-11 515, https://doi.org/10.1002/2016JD025057.

Salmond, J., and I. McKendry, 2005: A review of turbulence in the very stable nocturnal boundary layer and its implications for air quality. Prog. Phys. Geogr., 29, 171-188, https://doi.org/ 10.1191/0309133305pp442ra.

Sandu, I., A. Beljaars, P. Bechtold, T. Mauritsen, and G. Balsamo, 2013: Why is it so difficult to represent stably stratified conditions in numerical weather prediction (NWP) models? J. Adv. Model. Earth Syst., 5, 117-133, https://doi.org/10.1002/jame.20013.

Staley, D., and G. Jurica, 1972: Effective atmospheric emissivity under clear skies. J. Appl. Meteor., 11, 349-356, https://doi.org/ 10.1175/1520-0450(1972)011<0349:EAEUCS > 2.0.CO;2.

Steeneveld, G.-J., 2014: Current challenges in understanding and forecasting stable boundary layers over land and ice. Front. Environ. Sci., 2, 41, https://doi.org/10.3389/fenvs.2014.00041.

Steeneveld, G. J., B. J. H. Van de Wiel, and A. A. M. Holtslag, 2006: Modeling the evolution of the atmospheric boundary layer coupled to the land surface for three contrasting nights in CASES-99. J. Atmos. Sci., 63, 920-935, https://doi.org/10.1175/JAS3654.1.

Sun, J., and Coauthors, 2002: Intermittent turbulence associated with a density current passage in the stable boundary layer. Bound.-Layer Meteor., 105, 199-219, https://doi.org/10.1023/ A:1019969131774.

_- and Coauthors, 2004: Atmospheric disturbances that generate intermittent turbulence in nocturnal boundary layers. Bound.-Layer Meteor., 110, 255-279, https://doi.org/10.1023/ A:1026097926169.

_ L. Mahrt, R. M. Banta, and Y. L. Pichugina, 2012: Turbulence regimes and turbulence intermittency in the stable boundary layer during CASES-99. J. Atmos. Sci., 69, 338-351, https://doi.org/ 10.1175/JAS-D-11-082.1.

— - C. Nappo, and D. H. Lenschow, 2015: Wind and temperature oscillations generated by wave-turbulence interactions in the stably stratified boundary layer. J. Atmos. Sci., 72, 1484 1503, https://doi.org/10.1175/JAS-D-14-0129.1.

_ D. H. Lenschow, M. A. LeMone, and L. Mahrt, 2016: The role of large-coherent-eddy transport in the atmospheric surface layer based on CASES-99 observations. Bound.-Layer Meteor., 160, 83-111, https://doi.org/10.1007/s10546-016-0134-0.

Taylor, G. I., 1931: Effect of variation in density on the stability of superposed streams of fluid. Proc. Roy. Soc. London, 132A, 499-523, https://doi.org/10.1098/rspa.1931.0115.

Taylor, P., 1971: A note on the log-linear velocity profile in stable conditions. Quart. J. Roy. Meteor. Soc., 97, 326-329, https:// doi.org/10.1002/qj.49709741308.

Tjernström, M., and Coauthors, 2005: Modelling the arctic boundary layer: An evaluation of six ARCMIP regional-scale models using data from the SHEBA project. Bound.-Layer Meteor., 117, 337-381, https://doi.org/10.1007/s10546-004-7954-z.

van der Linden, S. J. A., P. Baas, J. Antoon van Hooft, I. G. S. van Hooijdonk, F. C. Bosveld, and B. J. H. van de Wiel, 2017
Local characteristics of the nocturnal boundary layer in response to external pressure forcing. J. Appl. Meteor. Climatol., 56, 3035-3047, https://doi.org/10.1175/JAMC-D-17-0011.1.

Van de Wiel, B. H. J., R. Ronda, A. F. Moene, H. De Bruin, and A. Holtslag, 2002a: Intermittent turbulence and oscillations in the stable boundary layer over land. Part I: A bulk model. J. Atmos. Sci., 59, 942-958, https://doi.org/10.1175/1520-0469(2002) 059<0942:ITAOIT $>2.0 . \mathrm{CO} ; 2$.

— A. F. Moene, R. Ronda, H. De Bruin, and A. Holtslag, 2002b: Intermittent turbulence and oscillations in the stable boundary layer over land. Part II: A system dynamics approach. J. Atmos. Sci., 59, 2567-2581, https://doi.org/10.1175/15200469(2002)059<2567:ITAOIT >2.0.CO;2.

,- , G. J. Steeneveld, O. K. Hartogensis, and A. A. M. Holtslag, 2007: Predicting the collapse of turbulence in stably stratified boundary layers. Flow Turbul. Combust., 79, 251-274, https://doi.org/10.1007/s10494-007-9094-2.

,-- , and H. J. J. Jonker, 2012a: The cessation of continuous turbulence as precursor of the very stable nocturnal boundary layer. J. Atmos. Sci., 69, 3097-3115, https://doi.org/10.1175/ JAS-D-12-064.1.

- $\longrightarrow,-$ P. Baas, S. Basu, J. M. M. Donda, J. Sun, and A. A. M. Holtslag, 2012b: The minimum wind speed for sustainable turbulence in the nocturnal boundary layer. J. Atmos. Sci., 69, 3116-3127, https://doi.org/10.1175/JAS-D-12-0107.1. , and Coauthors, 2017: Regime transitions in near-surface temperature inversions: A conceptual model. J. Atmos. Sci., 74, 1057-1073, https://doi.org/10.1175/JAS-D-16-0180.1.

Van Driest, E. R., 1951: On turbulent flow near a wall. J. Aeronaut. Sci., 18, 145-160, https://doi.org/10.2514/8.1895.

Van Hooijdonk, I. G. S., J. M. Donda, H. J. Clercx, F. C. Bosveld, and B. J. van de Wiel, 2015: Shear capacity as prognostic for nocturnal boundary layer regimes. J. Atmos. Sci., 72, 15181532, https://doi.org/10.1175/JAS-D-14-0140.1.

— , and Coauthors, 2017: Near-surface temperature inversion growth rate during the onset of the stable boundary layer. J. Atmos. Sci., 74, 3433-3449, https://doi.org/10.1175/JAS-D-17-0084.1.

Van Ulden, A. P., and J. Wieringa, 1996: Atmospheric boundary layer research at Cabauw. Boundary-Layer Meteorology 25th Anniversary Volume, 1970-1995, Springer, 39-69.

Vignon, E., and Coauthors, 2017: Stable boundary-layer regimes at Dome C, Antarctica: Observation and analysis. Quart. J. Roy. Meteor. Soc., 143, 1241-1253, https://doi.org/10.1002/qj.2998.

Viterbo, P., A. Beljaars, J.-F. Mahfouf, and J. Teixeira, 1999: The representation of soil moisture freezing and its impact on the stable boundary layer. Quart. J. Roy. Meteor. Soc., 125, 24012426, https://doi.org/10.1002/qj.49712555904.

Walters, D., and Coauthors, 2014: The Met Office Unified Model Global Atmosphere 4.0 and JULES Global Land 4.0 configurations. Geosci. Model Dev., 7, 361-386, https://doi.org/10.5194/ gmd-7-361-2014.

Walters, J. T., R. T. McNider, X. Shi, W. B. Norris, and J. R. Christy, 2007: Positive surface temperature feedback in the stable nocturnal boundary layer. Geophys. Res. Lett., 34, L12709, https://doi.org/10.1029/2007GL029505.

Webb, E. K., 1970: Profile relationships: The log-linear range, and extension to strong stability. Quart. J. Roy. Meteor. Soc., 96, 67-90, https://doi.org/10.1002/qj.49709640708.

Williams, A., S. Chambers, and A. Griffiths, 2013: Bulk mixing and decoupling of the nocturnal stable boundary layer characterized using a ubiquitous natural tracer. Bound.-Layer Meteor., 149, 381-402, https://doi.org/10.1007/s10546-013-9849-3. 